\title{
THE CLINICAL MANIFESTATIONS AND RESPONSE TO TREATMENT IN SOUTH AFRICANS WITH LUPUS NEPHRITIS
}

\author{
By \\ PRIYESH G MODY \\ Submitted in partial fulfilment of the academic requirements \\ for the degree of MMed \\ in the Department of Nephrology \\ School of Clinical Medicine \\ College of Health Sciences \\ University of KwaZulu-Natal \\ Durban \\ 2016
}

As the candidate's supervisor I have/hoved this thesis for submission.

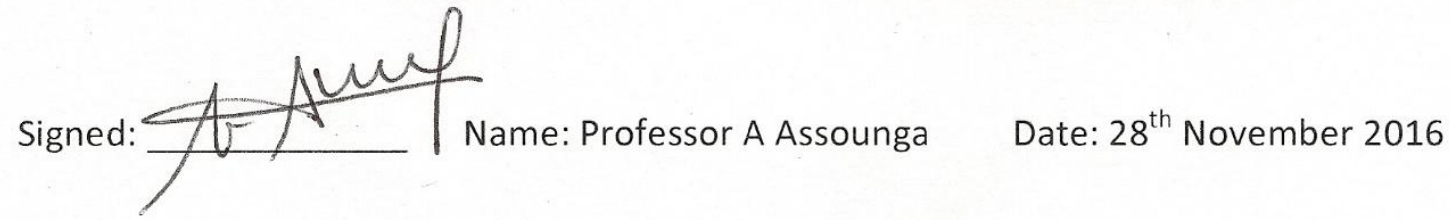




\section{Declaration}

\section{I, PRIYESH MODY declare that}

(i) The research reported in this dissertation, except where otherwise indicated, is my original work.

(ii) This dissertation has not been submitted for any degree or examination at any other university.

(iii) This dissertation does not contain other persons' data, pictures, graphs or other information, unless specifically acknowledged as being sourced from other persons.

(iv) This dissertation does not contain other persons' writing, unless specifically acknowledged as being sourced from other researchers. Where other written sources have been quoted, then:

a) their words have been re-written but the general information attributed to them has been referenced;

b) where their exact words have been used, their writing has been placed inside quotation marks, and referenced.

(v) Where I have reproduced a publication of which I am an author, co-author or editor, I have indicated in detail which part of the publication was actually written by myself alone and have fully referenced such publications.

(vi) This dissertation does not contain text, graphics or tables copied and pasted from the Internet, unless specifically acknowledged, and the source being detailed in the dissertation and in the References sections.

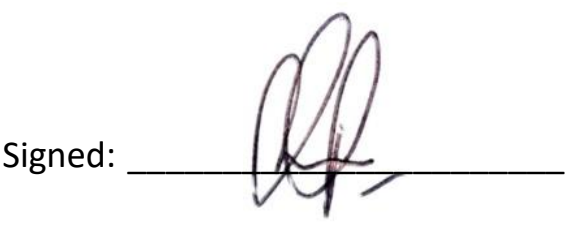

Date: $\quad 28^{\text {TH }}$ November 2016 


\section{Dedication}

I wish to dedicate this work to

my wife Praksha and

my children, Nikhil and Bhavya 


\section{Acknowledgements}

Professor Alain Assounga for his support and guidance

Professor Girish Mody for his encouragement and assistance

Ms Fikile Nkwanyana for statistical advice

Kristina Naidoo and Fundile Habana for their assistance with data capture, and data and statistical analysis.

The hospital management at Inkosi Albert Luthuli Central Hospital and the KwaZulu-Natal Department of Health for permission to conduct this study. 


\section{Presentations arising from this study}

1. Mody PG. "The Severity and Outcome of Lupus Nephritis in Clinical Practice" Oral paper presentation. Roche expert forum. $19^{\text {th }}$ February, 2012, Cape Town.

2. Mody PG; Mody GM; Ramdial PK; Haripershad S; Assounga A. "The Severity, Histological Classification and Treatment of Lupus Nephritis in Durban" Oral paper presentation. College of Health Sciences Research Symposium, $15^{\text {th }}$ September 2012, Durban

3. Mody PG; Mody GM; Ramdial PK; Haripershad S; Assounga A. "The Severity, Histological Classification and Treatment of Lupus Nephritis in Durban" Oral paper presentation. AFLAR \& SARAA, $3^{\text {rd }}-6^{\text {th }}$ April 2013. Durban

4. Mody PG; Mody GM; Ramdial PK; Haripershad S; Assounga A. "The Severity, Histological Classification and Treatment of Lupus Nephritis in Durban" Poster presentation. ISN World Congress of Nephrology, $31^{\text {st }}$ May $4^{\text {th }}$ June 2013, Hong Kong 


\section{Overview}

Systemic lupus erythematosus (SLE) is an uncommon disease which is being recognised with increasing frequency in Africa, including South Africa. It is most common in young women and is associated with a significant morbidity and mortality due to involvement of many organ systems. Lupus nephritis (LN) occurs in about $40-60 \%$ of patients with SLE and is one of the most common causes of morbidity and mortality in SLE. Reviews of LN in Africa have reported on the spectrum of histological involvement in SLE but there is limited information on the degree of renal impairment at presentation and the response to treatment and outcome. Over the past decade mycophenolate mofetil (MMF) has been widely used as an effective and safer treatment option compared to cyclophosphamide in the management of LN. However, MMF has only been used in $0.4-15.6 \%$ of patients with LN in Africa.

This study was undertaken as an audit of our clinical practice to determine the histological classification and renal function at presentation in patients with $L N$ seen at Inkosi Albert Luthuli Central Hospital (IALCH). We also undertook an assessment of the response to induction and maintenance therapy for LN and outcome of treatment during routine care in a tertiary referral centre. We wished to assess whether the presentation and response to treatment in Durban, South Africa is similar to the experience in other parts of the world. The multi-ethnic cohort of predominantly African blacks and Indians seen at our hospital, provided an opportunity to undertake an inter-ethnic comparison of the spectrum of histological classification, stage of chronic kidney disease at presentation, response to treatment and outcome.

We conducted a retrospective descriptive study by reviewing the hospital records of patients with SLE who were seen in the Departments of Nephrology and Rheumatology at Inkosi Albert Luthuli Central Hospital from 2003 to 2012. All the patients who had renal involvement and in whom the results of a baseline renal 
biopsy and baseline laboratory tests were available, were included in the study. The demographic data, results of the renal biopsy and baseline haematological, biochemical and immunological tests were recorded. The records of patients who had Class III and Class IV LN, with or without Class V changes, and patients with Class V LN alone, were analysed further to assess the response to 6 months' induction therapy and 12 months' maintenance therapy. The treatment for $L N$ and results of the follow up laboratory results were recorded.

The age at diagnosis of $L N$, gender, results of biochemical and immunological tests, histological classification, treatment and outcome were analysed for all the patients in the study, and separately for African Blacks and Indians as they comprised the majority of the patients in the study.

A separate analysis was performed for only those patients who required induction and maintenance therapy for LN (excluding patients with Class I, Class II and Class VI LN). We conducted an analysis of the demographic data, spectrum of histological classification, laboratory findings, stage of chronic kidney disease, treatment and outcome for all the treated patients and also compared the findings between African Blacks and Indians. A comparison of the patients with proliferative $\mathrm{LN}$ with membranous $\mathrm{LN}$ was undertaken to identify any differences in the demographic data, biochemical or immunological parameters, response to treatment and outcome.

The response to treatment was determined for 6 months of induction therapy and after maintenance therapy for 12 months. Patients who achieved a partial or complete remission were classified as responders and patients who did not respond to treatment, were lost to follow up or died, were classified as nonresponders. A further analysis of the responders and non-responders was undertaken to identify predictors of a poor response.

We identified 105 patients with LN who comprised 52 (49.5\%) Indians, 47 (44.8\%) African Blacks, 4 (3.8\%) Whites and 2 (1.9\%) Mixed ethnicity. We found that Class 
V LN was more common (34.3\%) than generally reported in most other studies. There was a higher prevalence of the milder Class II histology in our Indians while severe impairment of renal function (chronic kidney disease stage 5) was more common in African Blacks. There were 87 patients who required treatment for their LN. We found that $81.6 \%$ of our patients showed a response to induction therapy and $73.6 \%$ showed a response to maintenance therapy. Eight of our patients were lost to follow up prior to their final analysis and they were classified as nonresponders, thus contributing to lowering our response rate. International literature has shown a better response to MMF in African Americans compared to Caucasians. We have been able to confirm the efficacy of MMF as induction and maintenance therapy for the first time in our Indians and African Blacks.

Our study emphasizes the need to raise awareness of SLE among health professionals so that earlier diagnosis of LN can be made and patients can be treated before there is impaired renal function. We found that nearly $15 \%$ of our patients had stage 4 or stage 5 chronic kidney disease (eGFR $<30 \mathrm{ml} / \mathrm{min}$ ) at presentation, indicating significant impairment of renal function. We also found that there was a significant reduction in the response to treatment in patients who had a creatinine $\geq 132 \mu \mathrm{mol} / \mathrm{l}$ at presentation. This study contributes to the literature on lupus nephritis in Africa and we have shown that MMF is effective in our patients with LN. Thus it provides an alternative safer treatment option than the use of IV CYC. 


\section{Table of Contents}

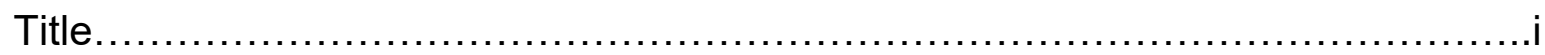

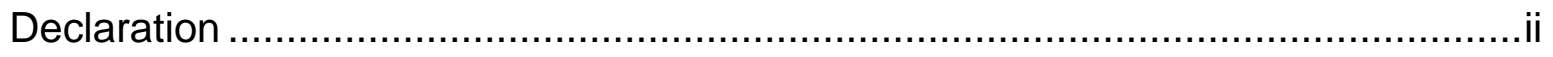

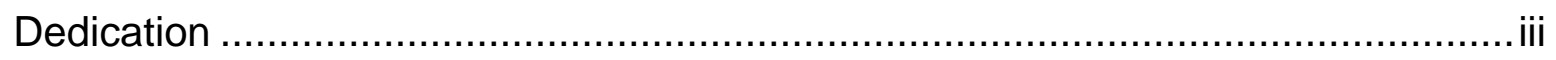

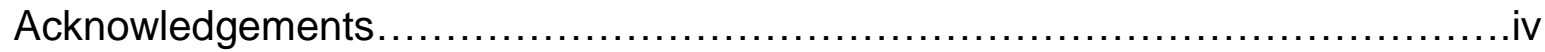

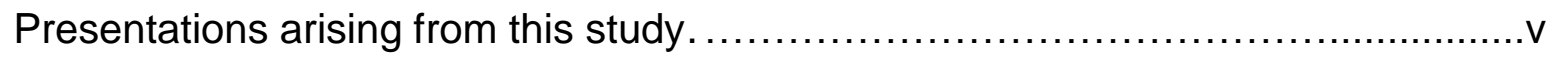

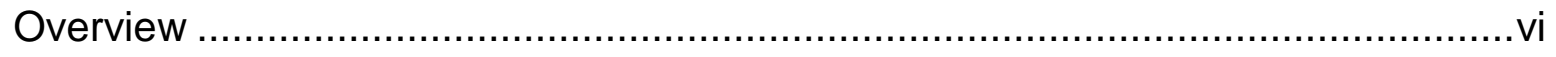

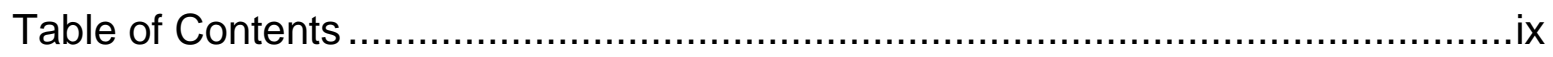

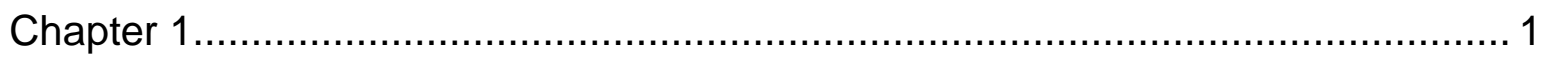

Chapter 2

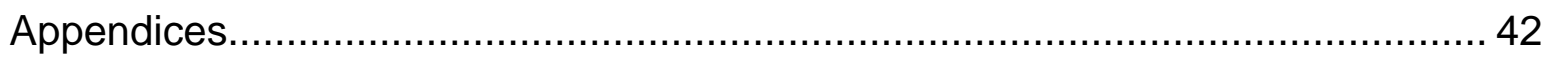

Appendix 1: The final Study Protocol ........................................................... 43

Appendix 2: The Guidelines for Authorship for the Journal .....................59

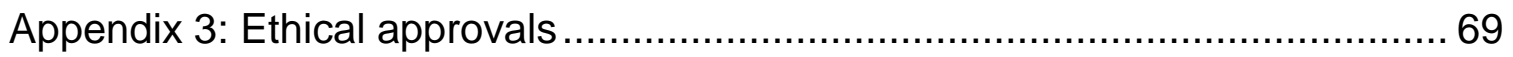

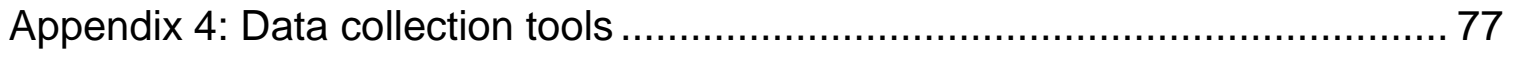

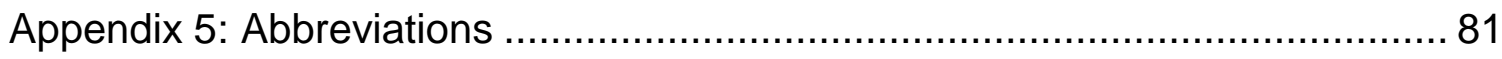




\section{Chapter 1}

\section{INTRODUCTION}

\section{OVERVIEW OF SYSTEMIC LUPUS ERYTHEMATOSUS}

Systemic lupus erythematosus (SLE) is a chronic multisystem autoimmune disease of unknown aetiology which is associated with a wide spectrum of clinical manifestations and is accompanied a range of immunological and laboratory abnormalities. The spectrum of the disease can vary from mild cutaneous or musculoskeletal involvement to severe involvement of organs such as the kidney and central nervous system. The important contribution of genetic factors to the susceptibility of the disease is supported by its occurrence in $24-58 \%$ of monozygotic twins and $2-5 \%$ of dizygotic twins, familial occurrence in $8-10 \%$ and the findings of genome wide association studies. ${ }^{1}$ Environmental factors such as smoking, viral infections and silica may trigger the development of the disease. The observations that $80-90 \%$ of the patients in most studies are females and that the highest risk for SLE is during the childbearing age, suggests that hormonal factors play an important role in SLE. ${ }^{2}$

A review of the epidemiology of SLE by Danchenko has shown that the prevalence of SLE is higher in non-Caucasian populations than in Caucasians. ${ }^{2}$ In the USA, SLE is more common in African Americans, Hispanics and Asians compared to Caucasians. ${ }^{1}$ There was a two to three-fold increase in the prevalence and incidence of SLE in African Americans compared to Caucasians. Johnson et al found that in Birmingham, UK, there was an increase in the incidence and prevalence of SLE in Afro-Caribbean's and Asian Indians compared to Caucasians. $^{3}$ The overall incidence of SLE (per 100,000 population/ year) has ranged from 1.0 to 4.8 in the Scandinavian countries, between 2 and 4.7 in the USA, Canada and the UK, to 8.7 in Brazil. The overall prevalence of SLE (per 
100,000 population) has ranged from 24.6 to 78.5 in the USA. ${ }^{1}$ Prevalence data from developing countries include rates of 12.2 in Black South Africans, 19.3 in Saudis, 60 in the Chinese in Hong Kong and 159 in Puerto Ricans. ${ }^{4}$ A systematic review noted considerable variation in the Asia Pacific region with incidence rates from 0.9 to $3.1 / 100,000$ per year and prevalence rates of 4.3 to $45.3 / 100,000$ population. ${ }^{5}$ A recent review of SLE in Africa has noted that there are limited epidemiological data with no large epidemiological study in sub-Saharan Africa. ${ }^{6}$ However, the increasing number of reports from different parts of Africa suggest than SLE may be more common than previously recognised.

The mean age of onset or diagnosis of SLE has varied from 24 - 26 years in Malaysia, Philippines and India, to 31 years in Europe and a peak incidence in the $50-54$ year age group in the UK. ${ }^{1}$ Ethnic and geographic variation has also been observed in the spectrum of clinical manifestations, severity of disease activity and damage accrual. ${ }^{1}$

There has been a marked improvement in the 5-year survival rate in SLE from $<50 \%$ in the 1950 s to nearly $95 \%$ in many parts of the world. ${ }^{1}$ Despite the improved survival, the standardised mortality ratios for SLE are 2 - 4 fold higher when compared to the general population. The $5,10,15$ and 20 - year survival rates in the Hopkins lupus cohort were 95\%, 91\%, 85\% and $78 \% .^{7}$ Lower 5 -year survival rates between $65 \%$ and $77 \%$ were reported from Singapore, Philippines, India and Thailand, and rates of between 57 and $72 \%$ were reported from South Africa. ${ }^{4,8}$

\section{LUPUS NEPHRITIS}

There is considerable variation in the spectrum of renal involvement in SLE ranging from mild asymptomatic haematuria, proteinuria or an abnormal urinary sediment to end-stage renal disease with renal failure. The prevalence of lupus nephritis (LN) ranged from $40-60 \%$ in most studies. ${ }^{9}$ In the Euro-lupus cohort of 1000 patients, comprising mainly Caucasians, the prevalence of nephritis was $27.9 \%{ }^{10}$ However a higher prevalence of $L N$ and increased risk of progression to end-stage 
renal disease has been observed in African Americans, Hispanics, AfroCaribbean's, Chinese and other Asian populations. ${ }^{9,} 11$ In the Hopkins lupus cohort of over 1500 patients, the risk of LN developing in African Americans was about $75 \% .^{12}$ In the LUMINA cohort, the prevalence of LN was $68.9 \%$ in African Americans, $60.6 \%$ in Hispanics and $29.1 \%$ in Caucasians after a mean follow up of 5.5 years. ${ }^{13}$ In the Asia-Pacific region, renal involvement was present in $21-65 \%$ at diagnosis and in $40-82 \%$ over time. ${ }^{5}$

The presence of renal involvement is one of the most important determinants of outcome in SLE. ${ }^{11}$ In a cohort of indigent South Africans, the most common causes of death were infection (32.7\%) and renal failure (16.7\%) with nephritis being the only independent predictor of mortality. ${ }^{8}$ While ethnicity and geographic location have been identified as possible causes of a poor outcome, socioeconomic variables such as poverty, level of education and lack of access to care may be more important. ${ }^{1,14}$

In a systematic review of $L N$ in Africa, Ameh et al noted that there was limited data on the diagnosis, management and outcome of $L N$ in Africa with only 16 publications from six countries. ${ }^{15}$ They found that proliferative LN (class III, class IV and mixed class $\mathrm{V}$ ) was most common and mortality ranged from $7.9 \%$ to $34.9 \%$. The majority of the patients received corticosteroids and cyclophosphamide based regimens while mycophenolate mofetil (MMF) was only used in $0.4 \%$ to $15.9 \%$ of all participants.

\section{Renal biopsy in suspected renal disease in SLE}

Early detection of renal involvement is important in patients with SLE. Patients with proteinuria, haematuria, cellular casts or impaired renal function, require a renal biopsy. Information about the histological class of $L N$ helps to guide treatment decisions. ${ }^{16,17}$ In addition, a biopsy will help to diagnose non-lupus lesions such as thrombotic microangiopathy, interstitial nephritis, focal glomerulosclerosis and IgA nephropathy. ${ }^{16}$ Patients with SLE may have antiphospholipid antibodies and are 
therefore at risk of developing thrombotic microangiopathy. Since musculoskeletal symptoms are common in SLE, the use of non-steroidal anti-inflammatory drugs increases the risk of interstitial nephritis. Based on the classification of the International Society of Nephrology and the Renal Pathology Society, information about the histological class and the activity and chronicity of the renal pathology can be obtained. Patients with Class I and Class II will benefit from renal protective measures such as control of hypertension and avoidance of nephrotoxic drugs. ${ }^{16}$ Patients with end-stage renal disease and Class VI histology, do not benefit from immunosuppressive therapy and require renal replacement therapy.

\section{The prevalence of the various histological classes of lupus nephritis}

A review of the prevalence of the various histological classes from studies around the world is shown in Table 6 in Chapter 2. The prevalence of Class I varies from 0 - $5 \%$ while Class II is noted about $10-15 \%$ of patients in most studies. The most common pattern of histological involvement is the presence of proliferative changes with class IV involvement in $40-70 \%$ of patients. A review of previous South African studies which reported the histological classification is shown in Table 1. There were a total of 475 renal biopsies in 471 patients from four academic centers in South Africa. ${ }^{8,18-21}$ The study period ranged three years to 17 years. ${ }^{8,19}$ There was a wide ethnic variation in the study populations with African Blacks comprising $92.9 \%$ of patients in Johannesburg and $53.5 \%$ in Durban while the majority of the patients in the Western Cape were patients of mixed ancestry. The prevalence of class V LN alone varied from $14,7 \%$ in Cape Town, $28.2 \%$ in Johannesburg to over $30 \%$ in two smaller studies in Durban. ${ }^{8,-21}$ Bhinder et al reported a series of 92 patients (91.3\% African Americans) in whom Class V was the most common histological class in $40.2 \% .{ }^{22}$ They noted a mean prevalence of membranous $L N$ in $14.05 \%$ in a review of a series of 9 other studies of $L N$. 
Apart from the studies shown in Table 1, Ayodele reported a series of 66 patients with proliferative nephritis and Okpechi reported 42 patients with membranous nephritis from Cape Town. ${ }^{23,24}$

Table 1: South African studies on lupus nephritis

\begin{tabular}{|l|l|l|l|l|l|l|}
\hline Author, year & $\begin{array}{l}\text { Halland, } \\
1991^{18}\end{array}$ & $\begin{array}{l}\text { Seedat, } \\
1994^{19}\end{array}$ & $\begin{array}{l}\text { Naicker, } \\
1997^{20}\end{array}$ & $\begin{array}{l}\text { Wadee, } \\
2007^{8}\end{array}$ & $\begin{array}{l}\text { Ayodele, } \\
2010^{23}\end{array}$ & $\begin{array}{l}\text { Okpechi, } \\
2012^{21}\end{array}$ \\
\hline Number of patients & 51 & 43 & 44 & 226 & 105 & 251 \\
\hline Number of renal biopsies & 55 & 43 & 44 & 82 & 105 & 251 \\
\hline $\begin{array}{l}\text { Histological } \\
\text { Classification }\end{array}$ & WHO & WHO & WHO & WHO & WHO & ISN/RPS \\
\hline Study period & $1983-1987$ & $1984-1987$ & $1988-1993$ & $1986-2003$ & $1995-2007$ & $2000-2009$ \\
\hline $\begin{array}{l}\text { Duration of follow-up in } \\
\text { months }\end{array}$ & $1.26 \pm 1.29$ & & & $\begin{array}{l}59.4 \\
49.0\end{array}$ & $51.1(1-137)$ & 120 \\
\hline F : M & $9.2: 1$ & $9.8: 1$ & $16.8: 1$ & $18: 1$ & $9.5: 1$ & $8.4: 1$ \\
\hline $\begin{array}{l}\text { Age at LN - mean } \pm \text { SD } \\
\text { years) }\end{array}$ & & 28 & 33 & $33.9 \pm 12.5$ & $31.9 \pm 10.3$ & $31.0 \pm 11.6$ \\
\hline $\begin{array}{l}\text { Mean creatinine. } \\
\text { ( } \mathrm{\mu mol/L)}\end{array}$ & $133 \pm 19$ & 202.4 & 191.8 & & $127 \pm 90$ & $178.2 \pm 210.5$ \\
\hline African Blacks \% & 5.9 & 53.5 & 65.9 & 92.9 & 20 & 17.5 \\
\hline Mixed ethnicity & 80.4 & 0 & 0 & 3.1 & 74.2 & 79.3 \\
\hline Indians & 0 & 46.5 & 34.1 & 3.1 & 2.9 & 0 \\
\hline Whites & 13.7 & 0 & 0 & 0.9 & 2.9 & 3.2 \\
\hline Class I & 0 & 21.7 & 0 & 1.2 & 0 & 0.4 \\
\hline Class II & 10.9 & 0 & 20.5 & 14.6 & 13.3 & 13.5 \\
\hline Class III & 23.6 & 26.1 & 2.3 & 36.6 & 7.6 & 20.7 \\
\hline Class IV & 58.2 & 21.7 & 22.7 & 17.1 & 55.2 & 20.7 \\
\hline Class V & 7.3 & 30.4 & 52.3 & 28.1 & 22.9 & 14.7 \\
\hline Class VI & 0 & 0 & 2.3 & 2.4 & 1 & 8.4 \\
\hline Mixed Classes & & & & & & 21.6 \\
\hline
\end{tabular}

\section{Assessment of response to treatment}

A variety of criteria have been used in different studies to define a complete or partial response in patients with LN and they were reviewed by Liu et al. ${ }^{25}$ In their meta-analysis of randomised controlled clinical trials undertaken from 2005 to 2012, they noted that the criteria for a complete remission included different values for the urine protein: creatinine ratio (UPCR) $(<0.3 \mathrm{~g} /$ day, $<0.4 \mathrm{~g} /$ day and $<0.5$ 
$\mathrm{g} /$ day) and the serum creatinine criterion also included in different values (return to a normal serum creatinine or return to within $10 \%$ of normal values or stabilization (within $20 \%$ ) or improvement in the serum creatinine).

The American College of Rheumatology (ACR) and European League Against Rheumatism (EULAR) recommend the use of urinalysis in the assessment of a complete renal response in LN. ${ }^{17,26}$ The response criteria have been widely used in many clinical trials including the recent rituximab and abatacept trials. However, many nephrologists do not consider micro haematuria as a predictive biomarker of renal response. ${ }^{27}$ Bose also expressed concern with the use of urinalysis as a response criterion as the number of cells and casts was influenced by the duration of the centrifuge and the manner in which the pellet at the bottom of the centrifuge was suspended in the supernatant. ${ }^{28}$ In the MAINTAIN nephritis trial, Tamirou et al found that proteinuria alone is the strongest predictor of a response to treatment. ${ }^{27}$ The addition of urinalysis did not improve the predictive value when used in combination with serum creatinine and proteinuria. The Joint EULAR and European Renal Association - European Dialysis and Transplant Association (EULAR/ ERA-EDTA) defined a complete response as a UPCR less than 50 $\mathrm{mg} / \mathrm{mmol}$ (proteinuria approximately $<0.5 \mathrm{~g} / 24$ hours) with a normal GFR or within $10 \%$ of the normal GFR if it was previously normal. A partial response was defined as $a \geq 50 \%$ reduction in the proteinuria to sub-nephrotic levels and a GFR which was normal or near normal. They also defined an improvement as any reduction in the proteinuria with a normal or stable GFR.

\section{Treatment and outcome of lupus nephritis}

The key principles in the management of $L N$ are the identification of patients at risk or the early diagnosis of LN, treatment with intensive immunosuppressive agents to control systemic inflammation, monitoring of the patients for persistent activity or a flare and to minimize the side effects of therapy. ${ }^{29}$ 
The use of intravenous (IV) cyclophosphamide (CYC) was considered to be the gold standard of treatment for $\mathrm{LN}$ following the findings of the National Institute of Health (NIH) study in $1986 .{ }^{30}$ The treatment regimen involved the use of CYC in a dose of $0.5-1.0 \mathrm{gm} / \mathrm{m}^{2}$ monthly for 6 months followed by repeat infusions every three months for a year. Patients also received treatment with parenteral corticosteroids or oral prednisone. The treatment was found to be more effective than azathioprine or prednisone alone in the preservation of renal function. Further studies at the NIH noted that prolonged treatment with CYC was associated with fewer nephritic flares and reduced risk of end-stage renal disease resulting in the recommendation to use monthly IV CYC for 6 doses followed by quarterly infusions for an additional 24 months. ${ }^{31}$ Following widespread use of IV CYC around the world, there were major concerns about toxicity such as leucopaenia, serious infections, hair loss, gonadal toxicity, haemorrhagic cystitis and risk of malignancy

The Euro-Lupus Nephritis Trial compared the efficacy of a low dose of CYC (2 weekly IV CYC for 6 doses) with the high dose NIH regimen (six pulses of IV CYC at monthly intervals followed by two pulses at quarterly intervals). ${ }^{32}$ Both groups received initial pulse methylprednisolone followed by tapering doses of prednisone and azathioprine as maintenance therapy after the course of IV CYC. The majority $(84 \%)$ of the patients in this study were white and at inception $22 \%$ had a raised serum creatinine and $28 \%$ had nephrotic range proteinuria. The authors found that the low dose regimen showed comparable efficacy in renal outcomes and a lower risk of serious infections. A 10 year follow up study showed similar renal outcomes even though most patients still required continuation of immunosuppressive therapy.

The efficacy of MMF as induction therapy for $L N$ has been shown in randomised controlled trials. The initial study of 42 patients by Chan et al ${ }^{33}$ was followed by a study of 140 patients by Ginzler et al ${ }^{34}$ and 370 patients by Appel et al. ${ }^{35}$ African Americans and Hispanics showed a better response to MMF than IV CYC. Lu et al found that MMF was effective as induction therapy in an open label study of 213 
Chinese. They achieved a remission rate of $82.4 \%$ (complete in $34.3 \%$ and partial in $48.4 \%$ ) and noted that the adverse prognostic factors were an elevated baseline creatinine and the presence of membranous involvement in addition to proliferative $\mathrm{LN}^{36}$ Liu et al conducted a meta-analysis of 725 patients with $\mathrm{LN}$ who received MMF or IV CYC as induction therapy in randomised controlled trials. ${ }^{25}$ They noted the superiority of MMF in producing a renal remission and preventing end stage renal disease or death. Although diarrhea was more common with MMF, leucopaenia, alopecia and amenorrhoea were less common.

Mycophenolate mofetil has been shown to be effective as induction and maintenance therapy and is associated with a lower incidence of side effects. In a long term follow up study, Chan et al showed that MMF was effective as induction and maintenance therapy when compared to IV CYC followed by azathioprine and MMF was associated with fewer infections. ${ }^{37}$ In 2004, Contreras showed that in patients who received induction therapy with IV CYC, the use of MMF or azathioprine was more effective and safer as maintenance therapy than IV CYC. ${ }^{38}$

In view of the important role of $B$ cells in the pathogenesis of $L N$, Rituximab has been used in patients with LN. In the Lupus Nephritis Assessment with Rituximab (LUNAR) Study, the addition of rituximab to MMF and corticosteroids failed to improve clinical outcomes at one year. ${ }^{39}$ However, a literature review of the use of rituximab in 300 patients with refractory LN, showed efficacy of $87 \%$ in Class III, $76 \%$ in Class IV and $67 \%$ in Class V LN. ${ }^{29}$

Chen et al studied 81 patients with $\mathrm{LN}$ and showed similar outcomes after six months' induction therapy in patients on tacrolimus $(n=42)$ and IV CYC $(n=39) .{ }^{40}$ Tacrolimus and cyclosporine have also been shown to be effective as induction therapy in smaller studies of patients with LN. ${ }^{41,42}$

\section{CONCLUSION}


Over the past decade there have been considerable advances in the management and outcomes of patients with LN. The comparable efficacy of low dose IV CYC to the high dose IV CYC regimen has provided a safer treatment option. In addition, the efficacy of MMF as induction and maintenance therapy in LN has also provided a safer alternative and avoided the need for parenteral therapy in many patients. Azathioprine continues to serve as an effective alternative for maintenance therapy in LN. Rituximab is effective in patients with refractory LN. Newer treatment strategies have also included the use of combination therapy with tacrolimus to further improve renal outcomes.

Patients with LN still face many challenges as relapses are frequent. Therefore, patients require careful monitoring to detect renal flares which require immediate treatment to prevent progression to end stage renal disease. There is also an unmet need to identify biomarkers which may help to predict a relapse. The management of LN needs to be individualized as LN often occurs in the setting of multi-organ involvement in SLE.

Despite the above advances, the management of $L N$ remains a major problem in developing countries where there are limited resources for renal replacement therapy. Even drugs such as MMF are not available to patients in many countries in Africa. However, we were fortunate to have access to MMF and report our experience in a multi-ethnic cohort. 


\section{REFERENCES}

1. Borchers AT, Naguwa SM, Shoenfeld Y, Gershwin ME. The geoepidemiology of systemic lupus erythematosus. Autoimm Rev 2010; 9: A277-A87.

2. Danchenko N, Satia J, Anthony M. Epidemiology of systemic lupus erythematosus: a comparison of worldwide disease burden. Lupus 2006; 15: 308-18.

3. Johnson AE, Gordon C, Palmer RG, Bacon PA. The prevalence and incidence of systemic lupus erythematosus in Birmingham, England. Relationship to ethnicity and country of birth. Arthritis Rheum 1995; 38: 5518.

4. Tikly M, Navarra SV. Lupus in the developing world - is it any different? Best Pract Res Clin Rheumatol 2008; 22: 643-55.

5. Jakes RW, Bae SC, Louthrenoo W, Mok CC, Navarra SV, Kwon N. Systematic review of the epidemiology of systemic lupus erythematosus in the Asia-Pacific region: prevalence, incidence, clinical features, and mortality. Arthritis Care Res (Hoboken) 2012; 64: 159-68.

6. Tiffin N, Hodkinson B, Okpechi I. Lupus in Africa: can we dispel the myths and face the challenges? Lupus 2014; 23: 102-11.

7. Kasitanon N, Magder LS, Petri M. Predictors of survival in systemic lupus erythematosus. Medicine (Baltimore) 2006; 85: 147-56. 
8. Wadee S, Tikly M, Hopley M. Causes and predictors of death in South Africans with systemic lupus erythematosus. Rheumatology 2007; 46: 148791.

9. Borchers AT, Keen CL, Shoenfeld Y, Gershwin ME. Surviving the butterfly and the wolf: mortality trends in systemic lupus erythematosus. Autoimmun Rev 2004; 3: 423-53.

10. Cervera R, Khamashta MA, Font $\mathrm{J}$, et al. Morbidity and mortality in systemic lupus erythematosus during a 10-year period: a comparison of early and late manifestations in a cohort of 1,000 patients. Medicine 2003; 82: 299-308.

11. Lau C, Yin G, Mok M. Ethnic and geographical differences in systemic lupus erythematosus: an overview. Lupus 2006; 15: 715-9.

12. Petri M. Lupus in Baltimore: evidence-based 'clinical pearls' from the Hopkins Lupus Cohort. Lupus 2005; 14: 970-3.

13. Bastian HM, Roseman JM, McGwin G, Jr., et al. Systemic lupus erythematosus in three ethnic groups. XII. Risk factors for lupus nephritis after diagnosis. Lupus 2002; 11: 152-60.

14. Alarcon GS. Of ethnicity, race and lupus. Lupus 2001; 10: 594-6.

15. Ameh OI, Kengne AP, Jayne D, et al. Standard of treatment and outcomes of adults with lupus nephritis in Africa: a systematic review. Lupus 2016.

16. Bihl GR, Petri M, Fine DM. Kidney biopsy in lupus nephritis: look before you leap. Nephrol Dial Transplant 2006; 21: 1749-52.

17. Bertsias GK, Tektonidou M, Amoura Z, et al. Joint European League Against Rheumatism and European Renal Association-European Dialysis and Transplant Association (EULAR/ERA-EDTA) recommendations for the management of adult and paediatric lupus nephritis. Ann Rheum Dis 2012; 71: 1771-82.

18. Halland AM, Bates WD, Tribe RD, Cooper R, Chalton D, Klemp P. Lupus nephritis. Part II. A clinicopathological correlation and study of outcome. S Afr Med J 1991; 79: 260-4. 
19. Seedat $\mathrm{Y}$, Parag K, Ramsaroop R. Systemic lupus erythematosus and renal involvement. Nephron 1994; 66: 426-30.

20. Naiker IP, Chrystal V, Randeree IG, Seedat YK. The significance of arterial hypertension at the onset of clinical lupus nephritis. Postgrad Med $J$ 1997; 73: 230-3.

21. Okpechi IG, Swanepoel CR, Tiffin N, Duffield M, Rayner BL. Clinicopathological insights into lupus nephritis in South Africans: a study of 251 patients. Lupus 2012; 21: 1017-24.

22. Bhinder $S$, Singh $A$, Majithia $V$. Membranous (class $V$ ) renal disease in systemic lupus erythematosus may be more common than previously reported: results of a 6-year retrospective analysis. Am J Med Sci 2010; 339: 230-2.

23. Ayodele OE, Okpechi IG, Swanepoel CR. Predictors of poor renal outcome in patients with biopsy-proven lupus nephritis. Nephrology (Carlton) 2010; 15: 482-90.

24. Okpechi IG, Ayodele OE, Jones ES, Duffield M, Swanepoel CR. Outcome of patients with membranous lupus nephritis in Cape Town South Africa. Nephrol Dial Transplant 2012; 27: 3509-15.

25. Liu LL, Jiang Y, Wang LN, Yao L, Li ZL. Efficacy and safety of mycophenolate mofetil versus cyclophosphamide for induction therapy of lupus nephritis: a meta-analysis of randomized controlled trials. Drugs 2012; 72: 1521-33.

26. The American College of Rheumatology response criteria for proliferative and membranous renal disease in systemic lupus erythematosus clinical trials. Arthritis Rheum 2006; 54: 421-32.

27. Tamirou F, D'Cruz D, Sangle S, et al. Long-term follow-up of the MAINTAIN Nephritis Trial, comparing azathioprine and mycophenolate mofetil as maintenance therapy of lupus nephritis. Ann Rheum Dis 2016; 75: 526-31.

28. Bose B, Silverman ED, Bargman JM. Ten common mistakes in the management of lupus nephritis. Am J Kidney Dis 2014; 63: 667-76. 
29. Weidenbusch M, Rommele C, Schrottle A, Anders HJ. Beyond the LUNAR trial. Efficacy of rituximab in refractory lupus nephritis. Nephrol Dial Transplant 2013; 28: 106-11.

30. Austin HA, 3rd, Klippel JH, Balow JE, et al. Therapy of lupus nephritis. Controlled trial of prednisone and cytotoxic drugs. N Engl J Med 1986; 314: 614-9.

31. Illei GG, Austin HA, Crane M, et al. Combination therapy with pulse cyclophosphamide plus pulse methylprednisolone improves long-term renal outcome without adding toxicity in patients with lupus nephritis. Ann Intern Med 2001; 135: 248-57.

32. Houssiau FA, Vasconcelos C, D'Cruz D, et al. Immunosuppressive therapy in lupus nephritis: the Euro-Lupus Nephritis Trial, a randomized trial of lowdose versus high-dose intravenous cyclophosphamide. Arthritis Rheum 2002; 46: 2121-31.

33. Chan TM, Li FK, Tang CS, et al. Efficacy of mycophenolate mofetil in patients with diffuse proliferative lupus nephritis. Hong Kong-Guangzhou Nephrology Study Group. N Engl J Med 2000; 343: 1156-62.

34. Ginzler EM, Dooley MA, Aranow C, et al. Mycophenolate mofetil or intravenous cyclophosphamide for lupus nephritis. New Engl J M 2005; 353: 2219-28.

35. Appel GB, Contreras G, Dooley MA, et al. Mycophenolate mofetil versus cyclophosphamide for induction treatment of lupus nephritis. J Am Soc Nephrol 2009; 20: 1103-12.

36. Lu F, Tu Y, Peng X, et al. A prospective multicentre study of mycophenolate mofetil combined with prednisolone as induction therapy in 213 patients with active lupus nephritis. Lupus 2008; 17: 622-9.

37. Chan TM, Tse KC, Tang CS, Mok MY, Li FK. Long-term study of mycophenolate mofetil as continuous induction and maintenance treatment for diffuse proliferative lupus nephritis. J Am Soc Nephrol 2005; 16: 107684. 
38. Contreras G, Pardo V, Leclercq B, et al. Sequential Therapies for Proliferative Lupus Nephritis. New Engl J Med 2004; 350: 971-80.

39. Rovin $\mathrm{BH}$, Furie $\mathrm{R}$, Latinis $\mathrm{K}$, et al. Efficacy and safety of rituximab in patients with active proliferative lupus nephritis: the Lupus Nephritis Assessment with Rituximab study. Arthritis Rheum 2012; 64: 1215-26.

40. Chen $W$, Tang $X$, Liu $Q$, et al. Short-term outcomes of induction therapy with tacrolimus versus cyclophosphamide for active lupus nephritis: A multicenter randomized clinical trial. Am J Kidney Dis 2011; 57: 235-44.

41. Li X, Ren H, Zhang Q, et al. Mycophenolate mofetil or tacrolimus compared with intravenous cyclophosphamide in the induction treatment for active lupus nephritis. Nephrol Dial Transplant 2012; 27: 1467-72.

42. Zavada J, Pesickova S, Rysava R, et al. Cyclosporine A or intravenous cyclophosphamide for lupus nephritis: the Cyclofa-Lune study. Lupus 2010; 19: $1281-9$. 


\section{Chapter 2}

\section{THE CLINICAL MANIFESTATIONS AND RESPONSE TO TREATMENT IN SOUTH AFRICANS WITH LUPUS NEPHRITIS}

Author Information:

Priyesh G Mody ${ }^{1}$

Girish M Mody ${ }^{2}$

Alain Assounga ${ }^{1}$

Authors affiliations:

${ }^{1}$ Department of Nephrology, School of Clinical Medicine, University of Kwa Zulu-

Natal and Inkosi Albert Luthuli Central Hospital, Durban

${ }^{2}$ Department of Rheumatology, School of Clinical Medicine, University of KwaZuluNatal and Inkosi Albert Luthuli Central Hospital, Durban

Corresponding author:

Priyesh G Mody

ADDRESS: P.O. Box 37924, Overport, Durban, South Africa, 4067

TELEPHONE NUMBER: Office: +27 $312516963 \quad$ Mobile: +27 845554583

FAX NUMBER: +27 866539727

e-mail: priyeshmody@gmail.com 


\title{
THE CLINICAL MANIFESTATIONS AND RESPONSE TO TREATMENT IN SOUTH AFRICANS WITH LUPUS NEPHRITIS
}

\begin{abstract}
Ethnicity plays a role in the clinical spectrum and response to treatment in lupus nephritis (LN). We studied a multi-ethnic South African cohort with LN to determine the clinical manifestations, histological involvement and response to induction and maintenance therapy. We conducted a retrospective review of the records of patients with $L N$ seen at the Inkosi Albert Luthuli Central Hospital in Durban. There were 106 patients, 92.5\% females and they comprised 49.1\% Indians and $45.3 \%$ African Blacks. The mean age of the patients was $31.3 \pm 12.5$ years, and $41.5 \%$ had $L N$ at first presentation of lupus. The most common histological classes were Class V alone in $34.9 \%$, Class IV ( \pm Class V) in $25.5 \%$ and Class III ( \pm Class V) in $22.6 \%$. A reduction in the estimated glomerular filtration rate (<30 ml/min) was noted in $15(14.2 \%)$ at presentation. Eighty-seven patients received therapy for $L N$. At baseline, Indians had a significantly lower C4 than African Blacks but there were no other significant differences between the groups. There was an overall response (partial or complete) to induction therapy in $81.6 \%$ and 12-months maintenance therapy in 73.6\%. Response to mycophenolate mofetil (MMF) was 80.4\% during induction therapy and 68.4\% - 78.0\% response during maintenance therapy. In conclusion, we note a high prevalence of membranous LN and a good response to treatment, including MMF, in our multiethnic cohort.
\end{abstract}

Key words

Systemic lupus erythematosus Lupus nephritis Ethnicity

African Blacks Indians Mycophenolate mofetil 
Running title: Lupus nephritis in South Africans

\section{Introduction}

Lupus nephritis (LN) remains one of the most important predictors of morbidity and mortality in systemic lupus erythematosus (SLE). The cumulative prevalence of LN varies from about $20-30 \%$ in Caucasians to about $50-70 \%$ in patients of African ancestry, Hispanics, Latin Americans and Asians. ${ }^{1-5}$ The spectrum of manifestations may vary from asymptomatic proteinuria or haematuria to overt nephrotic syndrome or acute renal failure. There has been a marked improvement in the outcome of LN. In the Euro-Lupus cohort of 1000 patients, $97.1 \%$ of whom were Whites, the 10 year survival in patients with nephritis was $88 \%{ }^{2} \mathrm{~A}$ recent study of an international multi-ethnic inception cohort of 1827 patients (38.3\% of whom had LN), reported an estimated 10 year survival of $94.5 \%$ in patients with nephritis. ${ }^{1}$ However, a poorer outcome is still reported in many of the developing countries. $^{6-8}$ The poor prognostic factors include the severity of the histological changes, the degree of renal impairment and the presence of hypertension at presentation.., 10 Ethnicity and socio-economic factors also play a role as African Americans and Hispanics have a poorer outcome for the same histological classification when compared to Caucasians. ${ }^{9-11}$

The improved outcome in patients with $L N$ has been attributed to many factors. They include earlier detection of $L N$ as a result of greater awareness, the use of safer treatment regimens and greater access to renal replacement therapy in many parts of the world. The traditional management of LN involved the use of high doses of intravenous cyclophosphamide (CYC) and corticosteroids. The use of lower doses of CYC in the Euro-Lupus study, mycophenolate mofetil (MMF) as induction and maintenance therapy, calcineurin inhibitors $(\mathrm{CNI})$ and rituximab (RTX) has provided alternate effective treatment options which are less toxic. ${ }^{12-17}$ New strategies using triple therapy with corticosteroids, tacrolimus and MMF have been associated with higher remission rates in Chinese. ${ }^{18}$ Ethnic variations in the 
response to therapy have also been observed. ${ }^{13}$ The American College of Rheumatology (ACR) guidelines for $L N$ recommend $M M F$ as the preferred induction therapy for LN in African Americans ${ }^{19}$. In Hong Kong Chinese, MMF was effective as induction and maintenance therapy. ${ }^{20}$ However, Rovin et al noted that CYC therapy still has a role in severe $L N$ as it is associated with fewer relapses. ${ }^{21}$

We undertook this study of a multiethnic cohort of SLE patients with LN in Durban, South Africa, to determine: 1) the histological classification and severity of renal impairment at presentation and 2) assess the response to treatment during routine care in a single academic centre.

\section{Methods}

We reviewed the records of all the patients with a diagnosis of SLE and renal involvement seen in the Departments of Nephrology and Rheumatology at Inkosi Albert Luthuli Central Hospital (IALCH) in Durban, South Africa from June 2003 to December 2012. The IALCH, a University affiliated tertiary hospital, was commissioned in 2003 to serve the public sector patients in the province of KwaZulu-Natal which has a population of nearly 10 million people. Patients who fulfilled the modified 1997 American College of Rheumatology Criteria ${ }^{22,23}$ for SLE and had evidence of renal involvement and biopsy proven LN with a positive antinuclear antibody, were eligible for inclusion in the study. Only patients who had a renal biopsy and in whom the baseline urea, creatinine, serum albumin, urine microscopy and chemistry, and 24-hour urine protein excretion or urine protein creatinine ratio (UPCR) were available, were included in the study to determine the pattern of histological involvement and stage of chronic kidney disease (CKD) at diagnosis of $L N{ }^{24}$ The estimated glomerular filtration rate (eGFR) was calculated according to the modification of the diet in renal disease formula. ${ }^{25}$ Based on the Kidney Disease Outcome Quality Initiative (KDOQI) guidelines, the eGFR $\left(\mathrm{ml} / \mathrm{min} / \mathrm{m}^{2}\right)$ was $\geq 90$ in stage $1,60-89$ in stage $2,30-59$ in stage $3,15-29$ in stage 4 and $<15$ in stage $5 .{ }^{24}$ The demographic data, age at onset of SLE, age at 
diagnosis of $L N$, presence of the ACR criteria and the results of the laboratory tests were recorded.

The findings on renal biopsy were classified according to the 1995 modification of the World Health Organization classification but patients with Class Vc and Vd are reported as Class III + V and Class IV + V respectively. ${ }^{26}$ Patients, who had Class III or Class IV LN with or without Class V LN, and Class V LN alone, were selected for the assessment of response to induction and maintenance therapy. Their files were analyzed further and the induction and maintenance therapy was recorded. The patients in the study were not managed according to a standardized protocol. The choice of treatment used as induction and maintenance therapy was dependent on the preference of the attending clinician. In the early part of the study, intravenous CYC was used for proliferative nephritis while pure membranous nephropathy was treated with corticosteroids alone. However, during the course of the study, MMF became more widely available and was used as induction and maintenance therapy for proliferative and membranous nephritis. In addition, when CYC was chosen, the Euro-Lupus regimen was used.

The urine and biochemistry results at baseline, after 6 months of induction therapy and after 12 months of maintenance therapy were recorded and analyzed. Patients were stratified as responders (if they had a complete or partial remission) or nonresponders, to induction and maintenance therapy. A complete remission was defined as a reduction in the proteinuria to $<0.5 \mathrm{~g} / 24$ hours with a normal serum creatinine. A partial remission was defined as a reduction in proteinuria to $<3 \mathrm{~g} / 24$ hours if it was in the nephrotic range or a reduction by more than $50 \%$ if it was in the sub-nephrotic range, accompanied by stabilization of the serum creatinine to \pm $25 \%$ of the baseline value or an improvement in the serum creatinine (reduction by more than $25 \%) .{ }^{14}$ Patients who failed to show a response, had deterioration of renal function (increase in the serum creatinine by more than $25 \%$ ), required renal replacement therapy, were lost to follow up or died were classified as nonresponders. The outcome of the patients was recorded as continuing follow up, lost 
to follow up or died. Patients who were lost to follow up or who died before the completion of the 12-month assessment on maintenance therapy were also classified as non-responders.

\section{Statistical tests}

The data was analyzed using SPSS version 22 (SPSS inc., Chicago, Illinois, USA). We compared the findings among the Indians and African Blacks, patients with proliferative nephritis to those with pure membranous involvement and among the responders and non-responders. The continuous variables are reported as means and standard deviation or as medians with inter-quartile range and the categorical variables are reported as numbers and percentages. The Pearson chi-square test or Fisher's exact test were used for categorical variables and the independent sample t-test was used for continuous variables.

\section{Results}

\section{Demographic data and manifestations of lupus nephritis}

There were 105 patients in whom the results of the baseline laboratory investigations and the results of the renal biopsy were available for analysis. They comprised 52 (49.5\%) Indians, 47 (44.8\%) African Blacks, four (3.8\%) Whites and two (1.9\%) Mixed ethnicity. The demographic data, results of laboratory investigations, histological classification and the stage of chronic kidney disease (CKD) are shown in Table 1.

The mean age at the onset of SLE of the overall cohort was $28.90 \pm 11.59$ years and $92.4 \%$ were females. There were $43(41.0 \%)$ patients in whom the LN was diagnosed at the first presentation of SLE and therefore the median interval from time of diagnosis of SLE to LN was 1.0 month (IQR 0-25.0 months). At the time of diagnosis of LN, 31 (29.5\%) had a serum creatinine $\geq 132 \mu \mathrm{mol} / \mathrm{l}$ and 37 (35.2\%) had nephrotic range proteinuria $>3.5 \mathrm{~g} / 24$ hours. The most common histological classification was Class V in 36 (34.3\%) patients and a further $23(21.9 \%)$ patients 
had membranous involvement in addition to proliferative changes. There were 26 patients (24.8\%) who had Class IV alone or IV + V and 25 (23.8\%) patients had Class III alone or III + V. There was impaired renal function with eGFR $<30 \mathrm{ml} / \mathrm{min}$ (CKD stage 4 and 5) in 15 (14.3\%) patients.

\section{Comparison of the manifestations of lupus nephritis in Indians and African Blacks}

The majority of the patients were Indians and African Blacks and the inter-ethnic comparison between these two groups is shown in Table 1. There was no difference in the mean age of onset, gender, interval between the diagnosis of SLE and diagnosis of $L N$ between the Indians and African Blacks. The only difference in the prevalence of the different histological classes was an increase in Class 2 among Indians compared to Africans (13.5\% vs $2.1 \%$ ) but this difference was not significant $(p=0.062)$. In comparison to Indians, the African Blacks had more severe renal impairment (stage 5 CKD in $14.9 \%$ vs $1.9 \%$; $p=0.025$ ) and significantly lower mean serum albumin $(27.04 \pm 8.15 \mathrm{~g} / \mathrm{l}$ vs $31.02 \pm 8.69 \mathrm{~g} / \mathrm{l} ; \mathrm{p}=0.024)$. There was no difference in the prevalence of nephrotic range proteinuria, number of patients with a raised serum creatinine $\geq 132 \mu \mathrm{mol} / \mathrm{l}$, anti-dsDNA antibodies and hypocomplementaemia.

\section{Baseline characteristics of patients treated for lupus nephritis}

The 18 patients who had Class I, Class II and Class VI LN did not receive immunosuppressive therapy for their LN. The remaining 87 patients received induction and maintenance treatment for $L N$. The baseline characteristics of these patients are shown in Table 2. They comprised 43 Indians, 42 African Blacks, one Mixed ethnicity and one White. The inter-ethnic comparison of the treatment cohort, showed that African Blacks had a higher prevalence of patients with eGFR $<30 \mathrm{ml} / \mathrm{min}$ (stage 4 and 5 in $19.0 \%$ vs $4.7 \% ; p=0.049$ ) and patients who were lost to follow up ( $16.7 \%$ vs $2.3 \% ; \mathrm{p}=0.030)$ while a low complement (C4) was more common in Indians (39.5\% vs $19.0 \% ; \mathrm{p}=0.038)$. African Blacks had a lower mean 
serum albumin $(26.88 \pm 7.78$ vs $30.24 \pm 9.11 \mathrm{~g} / \mathrm{l})$ but this difference was not statistically significant $p=0.077$ ). There was no difference in the gender, age of onset of SLE, interval between the diagnosis of SLE to the development of LN, prevalence of anti-dsDNA and histological classification of the $L N$.

\section{Comparison of patients with membranous and proliferative lupus nephritis}

We compared the findings in the 36 patients who had membranous nephritis (Class V) alone with 51 patients who had proliferative nephritis with or without membranous involvement (Class III alone or Class III $+\mathrm{V}$ and Class IV alone or Class IV and V) in Table 3. A larger number of patients with membranous $L N$ had nephrotic range proteinuria $(52.8 \%$ vs $31.4 \% ; p=0.045)$ and lower mean serum albumin (25.50 \pm 7.27 vs $30.62 \pm 8.82 \mathrm{~g} / \mathrm{l} ; \mathrm{p}=0.006$ ). There was no significant difference in the age at diagnosis of $L N$, prevalence of hypertension, prevalence of hypocomplementaemia, stage of CKD and response to treatment.

An assessment of the response to the different therapies used during the induction and maintenance phase in both groups is shown in Table 3. Majority of the patients in both groups were treated with MMF; cyclophosphamide was used mainly in patients with proliferative nephritis while prednisone alone was used mainly in patients with membranous involvement. We did not detect a difference in the response to treatment with MMF in patients with proliferative and membranous involvement. The numbers of patients in the other treatment groups was small.

\section{Response to treatment for lupus nephritis}

The response to treatment was analyzed at the end of 6 months of induction therapy and after a further 12 months of maintenance therapy in 87 patients who were treated for LN (Tables 2 and 4). The induction therapy used was MMF in 51 (58.6\%), CYC in $18(20.7 \%)$, prednisone in $17(19.5 \%)$ and one patient (1.1\%) received azathioprine (Table 2). Table 4 shows that overall there was a response (complete in 26 and partial in 45 ) in 71 (81.6\%) of the 87 patients to induction 
therapy $(72.2 \%$ for CYC, $80.4 \%$ for MMF and $94.1 \%$ for prednisone alone). One patient was lost to follow up before the completion of the induction phase.

The maintenance therapy group consisted of 57 (65.5\%) patients in the MMF treatment group (one of whom was lost to follow up before completion of the induction therapy), $18(20.7 \%)$ received prednisone alone, $10(11.5 \%)$ were on CYC and two (2.3\%) were on azathioprine. Only $75(86.2 \%)$ of the 87 patients were available for analysis after 12 months' maintenance therapy. Eight were lost to follow up (one of whom did not complete the induction phase) and four died before the completion of the maintenance phase. These patients were classified as non-responders. There was a response (complete in 35 and partial in 29) in 64 (73.6\%) of the 87 patients $(90 \%$ for CYC, $68.4 \%$ for MMF and $73.7 \%$ for prednisone alone) after 12 months' maintenance therapy.

The four patients who died included three with Class V LN and one with Class IV + $\mathrm{V} L N$; two of them had CKD stage 1 and two had CKD stage 3. The causes of death were active disease and infection in one patient and severe infection in three patients.

The inter-ethnic comparison in Table 2 showed that there was no significant difference in the overall response rate between African Blacks and Indians (69.0\% vs $79.1 \% ; p=0.292)$. Among the patients who received MMF, there was no significant difference in the response rate during induction and maintenance therapy. We noted a response in 16 (60.5\%) of 26 African Blacks and $18(75 \%)$ of the 24 Indians during induction therapy $(p=0.308)$ and in $17(60.7 \%)$ of 28 African Blacks and $21(77.8 \%)$ of 27 Indians during maintenance therapy $(p=0.171)$. Six of the African Blacks on MMF, were lost to follow up during the maintenance phase and were classified as non-responders. 


\section{Comparison of responders and non-responders}

A comparison of the 64 responders and the 23 non-responders (including the four deaths and eight patients lost to follow-up) is shown in Table 5. There was no difference in the age at diagnosis of SLE or LN, gender distribution, interval from diagnosis of SLE to LN, the mean number of classification criteria, prevalence of hypertension at baseline and the mean serum albumin. Among the nonresponders, there was a significant increase in the number of patients with a raised baseline creatinine $\geq 132 \mu \mathrm{mol} / \mathrm{l}(47.8 \%$ vs $20.3 \%$; $p=0.011)$, positive anti-dsDNA antibodies (87.0\% vs $50.0 \% ; \mathrm{p}=0.002)$ and a low C3 (87.0\% vs $50 \% ; \mathrm{p}=0.047)$. The prevalence of responders among the various histological classes was $84.0 \%$ (21 of 25 patients) for Class III and III + V, 73.1\% (19 of 26 patients) for Class IV and IV $+\mathrm{V}$ and $66.7 \%$ (24 of 36 patients) for Class V. Although patients with Class III and III + V had a better response, there was no significant difference between the groups.

\section{Discussion}

We report on the spectrum of histological findings and renal function in a multiethnic cohort of predominantly African Blacks and Indians with SLE seen during routine care at a single centre in Durban, South Africa. We also analyzed the response to six months of induction therapy and 12 months' maintenance therapy in patients who received treatment for proliferative and membranous nephropathy. There is very little information on the spectrum, treatment and outcome of $L N$ in sub-Saharan Africa. $^{8}$ In Hispanics, African American and Asians, renal involvement is more common, and they are reported to accrue more damage over time and at a faster rate than Caucasians. ${ }^{27-30}$ An ethnic gradient was noted in the UK with a prevalence of $L N / 100,000$ populations ranging from 110 in Chinese, 99.2 in Afro-Caribbean's, 21.4 in Indo-Asians and 5.6\% in whites. ${ }^{31}$

The severity of SLE and LN is increased in patients of African ancestry and in Indians. ${ }^{7,}{ }^{32}$ We studied 105 patients with LN and they included 52 (49.5\%) Indians 
and $47(44.8 \%)$ African Blacks (Table 1). The mean age of our patients at the diagnosis of $L N$ was $31.1 \pm 12.4$ years, which is similar to the $31.3 \pm 11.9$ years in the international cohort by Hanly et al, and $33.9 \pm 12.5$ and $31.9 \pm 10.3$ years in other South African studies, but higher than the $23.6 \pm 10.5$ years in India. ${ }^{1,}$ 7, 33, 34 Females accounted for $92.4 \%$ of our LN patients compared to $92.0 \%$ of the patients in India, $89.4 \%$ in China, and $84.2 \%$ to $86 \%$ in Spain, USA and an international cohort. ${ }^{1,7,9,35-37}$ In our study LN was present at the time of diagnosis of SLE in $43(41.0 \%)$ patients. A similar high prevalence of $39.3 \%$ of $163 \mathrm{LN}$ patients was reported by Singh et al in a predominantly African-American and Hispanic population in the USA. ${ }^{9}$ In the RELESSER study in Spain, 245 patients (22.4\%) had LN at onset of SLE and 56.3\% developed LN within 12 months. ${ }^{36}$ In the Euro-Lupus cohort of 1000 patients, the presence of nephropathy at the beginning of the study was associated with a significant reduction in survival (88\% vs $94 \% ; p=0.045) .^{2}$

We found that impaired renal function was more common in our patients as 18 (17.1\%) patients had CKD stage 3 and 15 (14.3\%) patients had stage 4 / 5 compared to a prevalence of stage 3 in $4.5 \%$ and stage $4 / 5$ in $2.0 \%$ in the international cohort of 652 patients by Hanly et al. ${ }^{1}$

The inter-ethnic comparison in our study (Table 1) showed that African Blacks had a lower mean serum albumin $(p=0.024)$ and more patients had stage 5 CKD function ( $p=0.025)$ - the latter may be related to African Blacks having more severe disease, a delay in presentation or referral due to access or socioeconomic circumstances. Although Class II LN was more common in Indians compared to Africans (13.5\% vs $2.1 \% ; p=0.062)$, there was no significant difference in the prevalence of the other histological classes between the two groups.

We compared the pattern of histological changes in our patients with other studies from Africa, two large pathology studies in the USA and UK, studies from different countries around the world and multicenter studies comprising an international cohort of patients (Table 6). The majority of the studies classified patients with 
mixed membranous or proliferative changes as Class III or Class IV, depending on the extent of the proliferative changes.

The prevalence of Class I ranged from $0-5 \%$ and Class II was around $10-15 \%$ in most clinical studies. A higher prevalence of Class I of $10.3 \%$ was noted in a pathology study in the UK, while Class II occurred in $33 \%$ of patients in a Japanese study. ${ }^{38,39}$ The prevalence of Class III (with or without Class V) was about 10-25\% in most studies, with a higher prevalence around 35\% being noted in an Egyptian, American and a South African study. ${ }^{9}, 33,40$ The most common histological class in most studies was diffuse proliferative involvement (Class IV) with prevalence around $40-70 \%$. The most common histological class in our patients was Class $\mathrm{V}$ (34.9\%) with a further $23(21.7 \%)$ having membranous involvement in addition to their Class III or Class IV proliferative changes. Bhinder et al reported a prevalence of isolated membranous involvement in $40.2 \%$ of their 92 patients (91.3\% African American). ${ }^{41}$ They found a mean prevalence of membranous $L N$ in $14.1 \%$ in a review of nine earlier studies. Membranous $L N$ was present in $31.8 \%$ of $L N$ in a large international cohort (50.8\% non-Caucasians), in $32 \%$ by Rivera et al ( $86 \%$ non-Caucasians), $29.4 \%$ by Seshan et al in the USA, $28.1 \%$ in a South African study (91.5\% African Blacks) and 27.4\% in Taiwan. ${ }^{1}$, 33, 37, 42, 43 The prevalence of membranous $L N$ ranged from 10 to $20 \%$ in the majority of the other studies in North Africa, Asia and Europe (Table 5).

In the past, the treatment of proliferative LN involved the use of CYC based on the $\mathrm{NIH}$ protocol or lower dose CYC Euro-Lupus regimen while membranous LN was initially treated with corticosteroids alone. ${ }^{12,}{ }^{44}$ Studies over the past decade have shown comparable efficacy (or superiority) and a better safety profile with the use of MMF as induction therapy compared to CYC. ${ }^{14,45,46}$ However, CYC still has a role as induction therapy in patients with severe renal involvement with very high creatinine levels or severe crescentic glomerulonephritis. ${ }^{21,47}$ In maintenance therapy, MMF was shown to be superior to or as effective as azathioprine, and both MMF and azathioprine were better than CYC. ${ }^{48,}{ }^{49}$ As a result of these 
observations MMF is recommended as initial therapy for proliferative $L N$, especially in African-American, Hispanic and Asian populations. ${ }^{5,}$ 19, 50 MMF is also recommended for the treatment of membranous $L N$ as it has similar efficacy to CYC. ${ }^{51} \mathrm{~A}$ recent review on $L N$ in Africa showed that most of the patients were treated with corticosteroids and CYC as induction therapy. ${ }^{8}$ There is limited data on MMF, with its reported use ranging from $0.4 \%$ to $15.6 \%$ of $L N .{ }^{8}$ In our study we found a response to six months of induction therapy 71 (81.6\%) of 87 patients and 12 months maintenance therapy in $64(73.6 \%)$ of 87 patients.

High remission rates during MMF induction therapy have ranged from 52\% (complete in $22.4 \%$ and partial $29.6 \%$ ) by Ginzler et al using strict criteria to $82.6 \%$ (complete $34.3 \%$ and partial $48.4 \%$ ) by Liu et al in a Chinese study. ${ }^{46,52}$ In the RELESSER study, $68.3 \%$ of the patients achieved complete remission with a normal serum creatinine and urinalysis. ${ }^{36}$ We found that $80.4 \%$ of our patients on MMF responded to induction therapy, and 68.4\% showed a response after 12 months maintenance therapy. Further sub-group analysis showed that 30 (83.3\%) of the 36 patients with proliferative nephritis and 11 (78.6\%) of patients with Class $\checkmark$ LN responded to MMF induction therapy. During maintenance therapy, a response to MMF was seen in $29(74.4 \%)$ of 39 patients with proliferative nephritis and 10 (55.6\%) of 18 patients with membranous nephritis. An inter-ethnic analysis did not show any difference in the response to MMF between Indians and African Blacks. Rivera et al showed a response to MMF in $70 \%$ and $73 \%$ of their patients with proliferative and membranous nephritis respectively. ${ }^{37}$ Chan et al showed that remission rates around $80 \%$ were achieved in patients who received either 12 months MMF or six months CYC followed by azathioprine..$^{53}$ In a long term follow up of 65 Chinese patients treated with MMF induction therapy followed by MMF, azathioprine or calcineurin inhibitors as maintenance therapy, the remission rates were $66.2 \%$ at 12 months, $80.0 \%$ at 24 months and $86.2 \%$ at 36 months. ${ }^{54}$ Nearly half of our patients with isolated membranous nephritis were treated with prednisone alone and they showed a good response to therapy. 
An analysis of our responders and non-responders showed that among the nonresponders, there was an increased number of patients with a raised baseline creatinine $\geq 132 \mu \mathrm{mol} / /$, positive anti-dsDNA antibodies and low C3. The degree of renal impairment at baseline has been reported as an adverse prognostic factor. ${ }^{10}$ We did not find any difference in the response to treatment among the various histological classes. Although a worse outcome is reported in patients with Class IV LN, several studies failed to detect a difference according to the class of nephritis. $^{7,10,34,55}$

As this is a retrospective study, there are many limitations associated with the study. It is likely that there was a bias towards relatively milder disease as a renal biopsy may not have been undertaken in patients with severe multisystem disease or patients who already had end stage renal disease and required renal replacement therapy. In addition, patients in whom the results of the baseline laboratory test or renal biopsy were not available, were excluded from the present study. The choice of treatment for the various histological classes was not standardized and depended on the discretion of the attending specialist.

In conclusion, we report the clinical presentation, pattern of histological involvement, baseline renal function, response to induction therapy and short-term response to maintenance therapy for $L N$ in a multi-ethnic cohort in a single centre in South Africa. We report a high prevalence of isolated membranous involvement in $34.9 \%$ compared to a prevalence of $10-20 \%$ in most Asian and Caucasian populations. Renal involvement occurred at presentation in $41.5 \%$ and impaired baseline renal function was more common. Despite the limitations of a retrospective study, we report a relatively large study of our experience with MMF in sub-Saharan Africa. We found that MMF is effective as induction and maintenance therapy in African Blacks and Indians in South Africa. Further studies are required to confirm these observations and determine the long-term response and outcome of treatment.

ACKNOWLEDGEMENTS 
We thank Ms Fikile Nkwanyana for statistical advice and Ms Kristina Naidoo and Mr Fundile Habana for assistance with data capture and statistical analysis.

\section{DISCLOSURES}

Dr PG Mody reports no conflict of interest

Professor GM Mody has received honoraria from Astra Zeneca (South Africa) and GlaxoSmithKline.

Professor A Assounga reports no conflict of interest

\section{FUNDING STATEMENT}

Financial support was obtained from the Aaron Beare Family Chair of Rheumatology Endowment Fund (financial support for a research assistant). 
TABLE 1: Baseline characteristics of patients with lupus nephritis ${ }^{\text {a }}$

\begin{tabular}{|c|c|c|c|c|}
\hline & $\begin{array}{c}\text { TOTAL } \\
(\mathrm{n}=105) \\
\mathrm{n}(\%)\end{array}$ & $\begin{array}{c}\text { Indians } \\
(n=52) \\
n(\%)\end{array}$ & $\begin{array}{c}\text { African Blacks } \\
(n=47) \\
n(\%)\end{array}$ & p-value \\
\hline Age at onset of SLE - mean \pm SD (years) & $28.90 \pm 11.59$ & $29.85 \pm 11.81$ & $28.11 \pm 11.40$ & 0.462 \\
\hline $\begin{array}{l}\text { Interval from SLE diagnosis to } L N \text { - mean } \\
\pm S D \text { (months) }\end{array}$ & $22.86 \pm 44.84$ & $25.00 \pm 42.52$ & $20.15 \pm 47.13$ & 0.594 \\
\hline $\begin{array}{l}\text { Duration from SLE diagnosis to } L N- \\
\text { median (IQR), months }\end{array}$ & $\begin{array}{l}1.0(0.0- \\
25.0)\end{array}$ & $\begin{array}{l}2.5(0.0- \\
31.7)\end{array}$ & $0.0(0.0-7.0)$ & 0.127 \\
\hline $\begin{array}{l}\text { Age at diagnosis of LN - mean } \pm \text { SD } \\
\text { (years) }\end{array}$ & $31.11 \pm 12.44$ & $31.76 \pm 11.91$ & $30.66 \pm 12.68$ & 0.654 \\
\hline Simultaneous diagnosis of SLE and LN & $43(41.0)$ & $18(34.6)$ & $24(51.1)$ & 0.098 \\
\hline Females & $97(92.4)$ & $47(90.4)$ & $45(95.7)$ & 0.440 \\
\hline Positive anti-ds DNA & $59(56.2)$ & $28(53.8)$ & $28(59.6)$ & 0.566 \\
\hline Low C3 (<0.90 g/l) & $58(55.2)$ & $24(46.2)$ & $30(63.8)$ & 0.078 \\
\hline Low C4 (<0.10 g/l) & $29(27.6)$ & $18(34.6)$ & $9(19.1)$ & 0.084 \\
\hline Serum albumin - mean $\pm S D g / L$ & $29.24 \pm 8.84$ & $31.02 \pm 8.69$ & $27.04 \pm 8.15$ & 0.024 \\
\hline Baseline creatinine $\geq 132 \mu \mathrm{mol} / \mathrm{l}$ & $31(29.5)$ & $12(23.1)$ & $17(36.2)$ & 0.153 \\
\hline Proteinuria $>3.5 \mathrm{~g} / 24$ hours & $37(35.2)$ & $18(34.6)$ & $17(36.2)$ & 0.872 \\
\hline \multicolumn{5}{|l|}{ Histology class n (\%) } \\
\hline Class I & $2(1.9)$ & $1(1.9)$ & $1(2.1)$ & 1.000 \\
\hline Class II & $12(11.4)$ & $7(13.5)$ & $1(2.1)$ & 0.062 \\
\hline Class III and Class III \& V & $25(23.8)$ & $14(26.9)$ & $10(21.3)$ & 0.513 \\
\hline Class III alone & $14(13.3)$ & $7(13.5)$ & $6(12.8)$ & \\
\hline Class III and V & $11(10.5)$ & $7(13.5)$ & $4(8.5)$ & \\
\hline Class IV and Class IV \& V & $26(24.7)$ & $14(26.9)$ & $12(25.5)$ & 0.875 \\
\hline Class IV alone & $14(13.3)$ & $7(13.5)$ & $7(14.9)$ & \\
\hline Class IV and V & 12 (11.4) & $7(13.5)$ & $5(10.6)$ & \\
\hline Class V & $36(34.3)$ & $15(28.8)$ & $20(42.6)$ & 0.154 \\
\hline Class VI & $4(3.8)$ & $1(1.9)$ & $3(6.4)$ & 0.260 \\
\hline \multicolumn{5}{|l|}{ Chronic kidney disease stage (eGFR) n (\%) } \\
\hline Stage $1(\geq 90 \mathrm{ml} / \mathrm{min}))$ & $52(49.5)$ & $28(53.8)$ & $21(44.7)$ & 0.362 \\
\hline Stage 2 ( $\geq 60$ to $<90 \mathrm{ml} / \mathrm{min}$ ) & $20(19.0)$ & $12(23.1)$ & $6(12.8)$ & 0.184 \\
\hline Stage 3 ( $\geq 30$ to $<60 \mathrm{ml} / \mathrm{min}$ ) & $18(17.1)$ & $8(15.3)$ & $10(21.3)$ & 0.448 \\
\hline Stage 4 ( $\geq 15$ to $<30 \mathrm{ml} / \mathrm{min}$ ) & $7(6.7)$ & $3(5.8)$ & $3(6.4)$ & 0.898 \\
\hline Stage $5(<15 \mathrm{ml} / \mathrm{min})$ & $8(7.6)$ & $1(1.9)$ & $7(14.9)$ & 0.025 \\
\hline
\end{tabular}


TABLE 2: Inter-ethnic comparison of the baseline characteristics, treatment and outcome of patients treated for lupus nephritis $(n=87)^{a}$

\begin{tabular}{|c|c|c|c|c|}
\hline & $\begin{array}{c}\text { TOTAL }(n=87) \\
n(\%)\end{array}$ & $\begin{array}{c}\text { Indians } \\
(\mathrm{n}=43) \\
\mathrm{n}(\%)\end{array}$ & $\begin{array}{c}\text { African Blacks } \\
(n=42) \\
n(\%)\end{array}$ & p-value \\
\hline Age at onset of SLE - mean \pm SD (years) & $28.55 \pm 11.90$ & $29.12 \pm 12.42$ & $28.44 \pm 11.56$ & 0.797 \\
\hline $\begin{array}{l}\text { Interval from SLE diagnosis to } L N \text { - mean } \\
\pm S D \text { (months) }\end{array}$ & $18.76 \pm 37.22$ & $20.54 \pm 34.53$ & $17.73 \pm 40.90$ & 0.735 \\
\hline $\begin{array}{l}\text { Age at diagnosis of } L N \text { - mean } \pm S D \\
\text { (years) }\end{array}$ & $30.51 \pm 12.33$ & $30.67 \pm 12.41$ & $30.91 \pm 12.41$ & 0.932 \\
\hline Simultaneous diagnosis of SLE and LN & $36(41.4)$ & $14(32.6)$ & $21(50.0)$ & 0.102 \\
\hline Females & $80(92.0)$ & $39(90.7)$ & $40(95.2)$ & 0.676 \\
\hline Positive anti-dsDNA & $52(59.8)$ & $25(58.1)$ & $25(59.5)$ & 0.897 \\
\hline Low C3 (<0.90 g/l) & $49(56.3)$ & $21(48.8)$ & $26(61.9)$ & 0.226 \\
\hline Low C4 (<0.10 g/l) & $26(29.9)$ & $17(39.5)$ & $8(19.0)$ & 0.038 \\
\hline Serum albumin - mean \pm SD g/L & $28.55 \pm 8.56$ & $30.24 \pm 9.11$ & $26.88 \pm 7.78$ & 0.077 \\
\hline Baseline creatinine $\geq 132 \mu \mathrm{mol} / \mathrm{l}$ & $24(27.6)$ & $9(20.9)$ & $14(33.3)$ & 0.198 \\
\hline Proteinuria $>3.5 \mathrm{~g} / 24$ hours & $35(40.2)$ & $17(39.5)$ & $17(40.5)$ & 0.929 \\
\hline \multicolumn{5}{|l|}{ Histology class $n(\%)$} \\
\hline Class III and Class III \& V & $25(28.7)$ & $14(32.6)$ & $10(23.8)$ & 0.370 \\
\hline Class III & $14(16.1)$ & $7(16.3)$ & $6(14.3)$ & \\
\hline Class III + V & $11(12.6)$ & $7(16.3)$ & $4(9.5)$ & \\
\hline Class IV and Class IV \& V & $26(29.9)$ & $14(32.6)$ & $12(28.6)$ & 0.690 \\
\hline Class IV & $14(16.1)$ & $7(16.3)$ & $7(16.7)$ & \\
\hline Class IV + V & $12(13.8)$ & $7(16.3)$ & $5(11.9)$ & \\
\hline Class V & $36(41.4)$ & $15(34.9)$ & $20(47.6)$ & 0.233 \\
\hline \multicolumn{5}{|l|}{ Chronic kidney disease (eGFR) n (\%) } \\
\hline Stage 1 ( $\geq 90 \mathrm{ml} / \mathrm{min})$ & $44(50.6)$ & $24(55.8)$ & $19(45.2)$ & 0.388 \\
\hline Stage 2 ( $\geq 60$ to $<90 \mathrm{ml} / \mathrm{min}$ ) & $17(19.5)$ & $10(23.3)$ & $6(14.3)$ & 0.268 \\
\hline Stage 3 ( $\geq 30$ to $<60 \mathrm{ml} / \mathrm{min}$ ) & $16(18.4)$ & $7(16.3)$ & $9(21.4)$ & 0.579 \\
\hline Stage 4 ( $\geq 15$ to $<30 \mathrm{ml} / \mathrm{min}$ ) & $4(4.6)$ & $1(2.3)$ & $3(7.1)$ & 0.306 \\
\hline Stage $5(<15 \mathrm{ml} / \mathrm{min})$ & $6(6.9)$ & $1(2.3)$ & $5(11.9)$ & 0.090 \\
\hline \multicolumn{5}{|l|}{ Treatment } \\
\hline Induction: Cyclophosphamide & $18(20.7)$ & $10(23.3)$ & $7(16.7)$ & 0.448 \\
\hline Mycophenolate mofetil & $51(58.6)$ & $24(55.8)$ & $26(61.9)$ & 0.568 \\
\hline Prednisone & 17 (19.5) & $9(20.9)$ & $8(19.0)$ & 0.828 \\
\hline Azathioprine & $1(1.1)$ & 0 & $1(2.4)$ & 0.494 \\
\hline Maintenance: Cyclophosphamide & $10(11.5)$ & $6(14.0)$ & $4(9.5)$ & 0.738 \\
\hline Mycophenolate mofetil & $57(65.5)$ & $27(62.8)$ & $28(66.7)$ & 0.709 \\
\hline Prednisone & $18(20.7)$ & $10(23.3)$ & $8(19.0)$ & 0.635 \\
\hline Azathioprine & $2(2.3)$ & 0 & $2(4.8)$ & 0.241 \\
\hline \multicolumn{5}{|l|}{ Outcome } \\
\hline Responders & 64 (73.6) & 34 (79.1) & $29(69.0)$ & 0.292 \\
\hline Non-responders to treatment & $11(12.6)$ & $6(14.0)$ & $4(9.5)$ & 0.738 \\
\hline Lost to follow up & $8(9.2)$ & $1(2.3)$ & $7(16.7)$ & 0.030 \\
\hline Death & $4(4.6)$ & $2(4.7)$ & $2(4.8)$ & 1.000 \\
\hline
\end{tabular}

${ }^{a}$ The total group includes one Mixed ethnicity male with Class V LN and one white female with Class III LN 
TABLE 3: Comparison of patients with membranous $L N$ alone with patients with proliferative changes with or without membranous involvement

\begin{tabular}{|c|c|c|c|c|}
\hline \multirow{2}{*}{\multicolumn{2}{|c|}{ Age at onset of SLE- mean \pm SD (years) }} & $\begin{array}{c}\text { Class III \& IV ( } n=51) \\
n(\%)\end{array}$ & $\begin{array}{c}\text { Class V (n=36) } \\
n(\%)\end{array}$ & p-value \\
\hline & & $28.24 \pm 11.94$ & $29.00 \pm 12.01$ & 0.772 \\
\hline \multicolumn{2}{|c|}{ Females } & $48(94.1)$ & $32(88.9)$ & 0.441 \\
\hline \multicolumn{2}{|c|}{$\begin{array}{l}\text { Age at diagnosis of } \mathrm{LN}-\text { mean } \pm \mathrm{SD} \\
\text { (years) }\end{array}$} & $29.71 \pm 11.72$ & $31.64 \pm 13.24$ & 0.475 \\
\hline \multicolumn{2}{|c|}{ Simultaneous diagnosis of SLE and LN } & $22(43.1)$ & $14(38.9)$ & 0.692 \\
\hline \multicolumn{2}{|c|}{$\begin{array}{l}\text { Interval from SLE diagnosis to LN - mean } \pm \\
\text { SD (months) }\end{array}$} & $16.77 \pm 30.02$ & $21.66 \pm 46.09$ & 0.552 \\
\hline \multicolumn{2}{|l|}{ Hypertension } & $12(23.4)$ & $15(41.7 \%)$ & 0.072 \\
\hline \multicolumn{2}{|c|}{ Baseline creatinine $>132 \mu \mathrm{mol} / \mathrm{l}$} & $14(27.5)$ & $10(27.8)$ & 0.973 \\
\hline \multicolumn{2}{|c|}{ Median (IQR) creatinine $(\mu \mathrm{mol} / \mathrm{l})$} & $90(65-165)$ & $71.5(55.3-153.8)$ & 0.184 \\
\hline \multicolumn{2}{|c|}{$\begin{array}{l}\text { Nephrotic range proteinuria } \\
(>3.5 \mathrm{~g} / 24 \text { hours) }\end{array}$} & $16(31.4)$ & $19(52.8)$ & 0.045 \\
\hline \multicolumn{2}{|c|}{ Serum albumin - mean \pm SD g/L } & $30.62 \pm 8.82$ & $25.50 \pm 7.27$ & 0.006 \\
\hline \multicolumn{2}{|c|}{ Number with low C3 $(<0.90 \mathrm{~g} / \mathrm{l})$} & $28(54.9)$ & $21(58.3)$ & 0.751 \\
\hline \multicolumn{2}{|c|}{ Number with low C4 $(<0.10 \mathrm{~g} / \mathrm{l})$} & $17(33.3)$ & $9(25.0)$ & 0.403 \\
\hline \multicolumn{2}{|c|}{ Number with positive anti-dsDNA } & $37(72.5)$ & $15(41.7)$ & 0.004 \\
\hline \multicolumn{5}{|c|}{ Chronic kidney disease (eGFR) } \\
\hline \multicolumn{2}{|c|}{ Stage $1(\geq 90 \mathrm{ml} / \mathrm{min}))$} & $25(49)$ & $19(52.8)$ & 0.730 \\
\hline \multicolumn{2}{|c|}{ Stage 2 ( $\geq 60$ to $<90 \mathrm{ml} / \mathrm{min}$ ) } & $13(25.5)$ & $4(11.1)$ & 0.096 \\
\hline \multicolumn{2}{|c|}{ Stage $3(\geq 30$ to $<60 \mathrm{ml} / \mathrm{min})$} & $7(13.8)$ & $9(25.0)$ & 0.181 \\
\hline \multicolumn{2}{|c|}{ Stage 4 ( $\geq 15$ to $<30 \mathrm{ml} / \mathrm{min})$} & $2(3.9)$ & $2(5.6)$ & 1.000 \\
\hline \multicolumn{2}{|c|}{ Stage $5(<15 \mathrm{ml} / \mathrm{min}$} & $4(7.8)$ & $2(5.6)$ & 0.678 \\
\hline \multicolumn{5}{|c|}{ Response to treatment } \\
\hline \multicolumn{2}{|l|}{ Responders } & $40(78.4)$ & $24(66.7)$ & 0.220 \\
\hline \multicolumn{2}{|c|}{ Non-responders to treatment } & $6(11.8)$ & $5(13.9)$ & 0.756 \\
\hline \multicolumn{2}{|c|}{ Lost to follow up } & $4(7.8)$ & $4(11.1)$ & 0.713 \\
\hline \multicolumn{2}{|l|}{ Deaths } & $1(2.0)$ & $3(8.3)$ & 0.302 \\
\hline \multicolumn{5}{|c|}{ Responders to specific treatment } \\
\hline \multirow[t]{4}{*}{ Induction: } & Cyclophosphamide & $10 / 13(76.9)$ & $3 / 5(60)$ & 0.583 \\
\hline & MMF & $30 / 36(83.3)$ & $11 / 15(73.3)$ & 0.454 \\
\hline & Prednisone & $1 / 1$ & $15 / 16(93.8)$ & 1.000 \\
\hline & Azathioprine & $1 / 1$ & 0 & - \\
\hline \multirow[t]{4}{*}{ Maintenance: } & Cyclophosphamide & $8 / 9(88.9)$ & $1 / 1$ & 0.200 \\
\hline & MMF & $29 / 39(74.4)$ & $10 / 18(55.6)$ & 0.527 \\
\hline & Prednisone & $1 / 1$ & $13 / 17(76.5)$ & 1.000 \\
\hline & Azathioprine & $2 / 2$ & 0 & - \\
\hline
\end{tabular}


Table 4: Response after 6 months of induction therapy and 12 months' maintenance therapy

\begin{tabular}{|l|c|c|c|c|c|c|c|c|}
\hline & \multicolumn{4}{|c|}{ Induction therapy (n=87) } & \multicolumn{4}{c|}{ Maintenance therapy (n=87) } \\
\cline { 2 - 9 } & CR & PR & Responders/total & $\begin{array}{c}\text { Responders } \\
(\%)\end{array}$ & CR & PR & Responders/total & $\begin{array}{c}\text { Responders } \\
(\%)\end{array}$ \\
\hline Cyclophosphamide & 6 & 7 & $13 / 18$ & 72.2 & 4 & 5 & $9 / 10^{\mathrm{b}}$ & 90 \\
\hline MMF & 16 & 25 & $41 / 51^{\mathrm{a}}$ & 80.4 & 22 & 17 & $39 / 57^{\mathrm{c}}$ & 68.4 \\
\hline Prednisone & 4 & 12 & $16 / 17$ & 94.1 & 8 & 6 & $14 / 18^{\mathrm{d}}$ & 77.8 \\
\hline Azathioprine & 0 & 1 & $1 / 1$ & 100 & 1 & 1 & 2 & 100 \\
\hline TOTAL & 26 & 45 & $71 / 87^{\mathrm{a}}$ & 81.6 & 35 & 29 & $64 / 87$ & 73.6 \\
\hline
\end{tabular}

$\mathrm{CR}$ - complete remission; PR - partial remission; MMF - mycophenolate mofetil;

${ }^{a}$ includes one patient who was lost to follow up during the induction phase

${ }^{b}$ includes one patient who died before the end of the maintenance phase

${ }^{c}$ includes seven patients who were lost to follow-up (one during induction phase and six during maintenance phase) and two patients who died during the maintenance phase

${ }^{d}$ includes one patient who was lost to follow up and one patient who died during the maintenance phase

Table 5: Comparison of responders and non-responders

\begin{tabular}{|l|c|c|c|}
\hline & $\begin{array}{c}\text { Responders } \\
(\mathbf{n = 6 4 )}\end{array}$ & $\begin{array}{c}\text { Non-responders } \\
(\mathbf{n = 2 3})^{\mathbf{a}}\end{array}$ & p value \\
\hline $\begin{array}{l}\text { Age at onset of SLE - mean } \\
\text { (years) SD }\end{array}$ & $29.10 \pm 12.01$ & $27.04 \pm 11.74$ & 0.482 \\
\hline $\begin{array}{l}\text { Age at diagnosis of LN - mean } \pm \text { SD } \\
\text { (years) }\end{array}$ & $31.09 \pm 12.39$ & $28.87 \pm 12.29$ & 0.461 \\
\hline $\begin{array}{l}\text { Interval from SLE diagnosis and LN } \\
- \text { mean } \pm \text { SD (months) }\end{array}$ & $18.78 \pm 34.47$ & $18.70 \pm 44.77$ & 0.994 \\
\hline Females $n(\%)$ & $60(93.8 \%)$ & $20(87 \%)$ & 0.304 \\
\hline Number of SLE criteria - mean \pm SD & $6.06 \pm 1.91$ & $6.65 \pm 1.80$ & 0.201 \\
\hline Hypertension at baseline & $19(29.7)$ & $8(34.8)$ & 0.651 \\
\hline eGFR $\leq 29 m \mathrm{~m} /$ min & $5(7.8 \%)$ & $5(21.7 \%)$ & 0.121 \\
\hline Baseline creatinine $\geq 132 \mu \mathrm{mol} / \mathrm{l}$ & $13(20.3 \%)$ & $11(47.8 \%)$ & 0.011 \\
\hline $\begin{array}{l}\text { Median }(\text { IQR) serum creatinine } \\
\mu m o l / l\end{array}$ & $77.0(62.5-115)$ & $119.0(48.0-278.0)$ & 0.176 \\
\hline Serum albumin - mean \pm SD g/L & $29.23 \pm 9.25$ & $26.64 \pm 5.99$ & 0.141 \\
\hline Positive anti-dsDNA antibodies & $32(50.0 \%)$ & $20(87.0 \%)$ & 0.002 \\
\hline Number with low C3 (<0.90 g/L) & $32(50 \%)$ & $17(73.9 \%)$ & 0.047 \\
\hline Number with low C4 (<0.10 g/L) & $20(31.3 \%)$ & $6(26.1 \%)$ & 0.643 \\
\hline
\end{tabular}

${ }^{a}$ The non-responders include eight patients who were lost to follow up (one during the induction phase and seven during the maintenance phase) and 4 patients who died during the maintenance phase. 
Table 6 Comparison of the histological classification of patients with lupus nephritis

\begin{tabular}{|c|c|c|c|c|c|c|c|c|c|c|c|c|}
\hline First author & Country / year & $\begin{array}{l}\text { WHO or } \\
\text { ISN/RPS }\end{array}$ & $\begin{array}{l}\text { Num } \\
\text { ber }\end{array}$ & I & II & III & III+V & IV & $\begin{array}{l}\text { IV+ } \\
\mathrm{V}\end{array}$ & $\mathbf{v}$ & VI & Mixed \\
\hline \multicolumn{13}{|l|}{ Africa } \\
\hline Present study & South Africa 2016 & WHO & 105 & 1.9 & 11.4 & 13.3 & 10.5 & 13.3 & 11.4 & 34.3 & 3.8 & \\
\hline Ayodele $\mathrm{OE}^{34}$ & South Africa 2010 & WHO & 105 & & 13.3 & 7.6 & & 55.2 & & 22.9 & 1.0 & \\
\hline Wadee $S^{33}$ & South Africa 2007 & WHO & 82 & 1.2 & 14.6 & 36.6 & & 17.1 & & 28.1 & 2.4 & $19.5 \%^{\mathrm{a}}$ \\
\hline Haddiyai $^{56}$ & Morocco 2013 & ISN/RPS & 96 & 3.1 & 2.1 & 10.4 & 2.1 & 62.5 & 8.3 & 8.3 & 3.1 & \\
\hline Khanfir $\mathrm{MS}^{57}$ & Tunisia 2013 & WHO & 264 & 4.1 & 14.2 & 25.8 & & 29.6 & & 9.7 & & $17.6 \%^{b}$ \\
\hline Mahmoud GA ${ }^{40}$ & Egypt 2015 & WHO & 135 & & 15.6 & 33.3 & 3.7 & 33.3 & & 11.1 & 2.9 & \\
\hline \multicolumn{13}{|l|}{ Asia } \\
\hline Wang $\mathrm{YF}^{58}$ & China 2012 & ISN/RPS & 315 & & 6.0 & $17.5^{c}$ & & $53.7^{d}$ & & 21.9 & 1.0 & \\
\hline Zheng $\mathrm{ZH}^{35}$ & China 2012 & ISN/RPS & 491 & 1.8 & 9.4 & 16.7 & 7.9 & 33.4 & 16.9 & 13.6 & 0.2 & \\
\hline Dhir V ${ }^{7}$ & India 2012 & WHO & 136 & & 16.2 & 26.5 & & 44.9 & & 11.8 & 0.7 & \\
\hline Kono $\mathrm{N}^{39}$ & Japan 2014 & ISN/RPS & 186 & 2.7 & 33.3 & 8.6 & 2.7 & 32.2 & 7.0 & 13.4 & & \\
\hline Yokoyama $\mathrm{H}^{59}$ & Japan 2011 & ISN/RPS & 480 & 3.1 & 16.0 & $12.9^{c}$ & & $51.3^{d}$ & & 15.6 & 1.0 & \\
\hline Wen $\mathrm{YK}^{43}$ & Taiwan 2011 & ISN/RPS & 131 & & 9.2 & 6.1 & 8.4 & 43.5 & 0.8 & 27.4 & & $4.6^{\mathrm{e}}$ \\
\hline \multicolumn{13}{|l|}{ Europe } \\
\hline Bono $L^{55}$ & UK 1999 & WHO & 110 & 0 & 21 & 25 & & 37 & & 17 & 0 & \\
\hline Furness $\mathrm{PN}^{38}$ & 2006 UK & $\begin{array}{l}\text { ISN/RPS } \\
+ \text { WHO }\end{array}$ & 507 & 10.3 & 12.6 & 12.2 & & 46.0 & & 18.9 & 0.6 & \\
\hline $\begin{array}{l}\text { Galindo-Izquiedo } \\
\mathrm{M}^{36}\end{array}$ & Spain 2016 & WHO & 1092 & 2.5 & 13.6 & 18.6 & 1.0 & 48.7 & 1.9 & 10.3 & 0.9 & $1.3 \%^{f}$ \\
\hline Cervera $\mathrm{R}^{60}$ & Europe 1993 & WHO & 270 & 5 & 13 & 23 & & 40 & & 14 & & \\
\hline \multicolumn{13}{|l|}{ Middle East } \\
\hline Al Durahim $\mathrm{H}^{61}$ & Saudi Arabia 2011 & ISN/RPS & 99 & & 17.9 & 2.6 & & 65.4 & & 14.1 & & \\
\hline $\begin{array}{l}\text { Shariati-Sarabi } \\
z^{62}\end{array}$ & Iran 2013 & ISN/RPS & 72 & 0 & 0 & 21.1 & & 52.1 & & 19.7 & 7.1 & \\
\hline \multicolumn{13}{|l|}{ USA } \\
\hline Contreras $\mathrm{G}^{63}$ & USA, 2006 & WHO & 213 & & 9.4 & 12.7 & & 51.6 & & 26.3 & & \\
\hline Bhinder $\mathrm{S}^{41}$ & USA 2010 & WHO & 92 & 0 & 9.8 & 8.7 & & 36.9 & & 40.2 & 4.3 & \\
\hline Singh $S^{9}$ & USA, 2011 & ISN/RPS & 163 & & 11 & 36 & & 39 & & 13.5 & 1 & \\
\hline Riviera $\mathrm{TL}^{37}$ & USA 2009 & ISN/RPS & 123 & & 5 & 22 & & 40 & & 32 & 2 & \\
\hline Seshan SV ${ }^{42}$ & USA 2009 & ISN/RPS & 541 & 0.9 & 10.0 & 7.2 & 12.6 & 29.8 & 6.8 & 29.4 & 3.3 & \\
\hline \multicolumn{13}{|l|}{ International } \\
\hline Hanly JG ${ }^{1}$ & Global 2016 & ISN/RPS & 377 & 2.4 & 9.5 & 21.2 & 5.6 & 34.2 & 9.0 & 31.8 & 0.8 & \\
\hline Ginzler EM ${ }^{46}$ & USA 2005 MC & WHO & 140 & & & 15.7 & & 54.3 & & 19.3 & & $10.7 \%^{\mathrm{g}}$ \\
\hline Appel GB ${ }^{14}$ & Global 2009 & ISN/RPS & 370 & & & $15.7^{c}$ & & $68.1^{d}$ & & 16.2 & & \\
\hline Dooley MA ${ }^{48}$ & Global 2011 & ISN/RPS & 227 & & & $12.8^{c}$ & & $71.8^{d}$ & & 15.4 & & \\
\hline Rovin $\mathrm{BH}^{64}$ & USA Mexico 2012 & ISN/RPS & 144 & & & 24 & 25 & 71 & 24 & & & \\
\hline
\end{tabular}

WHO-World Health Organization; ISN - International Society of Nephrology; RPS -Renal Pathology Society

${ }^{a}$ Apart from the 23 (28.1\%) patients with Class V alone, a further 16 (19.5\%) with Class II, III or IV also had membranous involvement; ${ }^{\mathrm{b}} 1.1 \%$ had Class II $+\mathrm{V}, 7.1 \%$ had Class III or IV $+\mathrm{V}, 6.7 \%$ had interstitial nephritis, and 2.7\% had renal vascular microthrombi; ${ }^{\mathrm{c}}$ includes patients with Class III alone or Class III + V ; ${ }^{\mathrm{d}}$ includes patients with Class IV alone or Class IV $+\mathrm{V} ;{ }^{\mathrm{e}} 4.6 \%$ had non-lupus nephropathy; ${ }^{\mathrm{f}}$ includes 2 patients $1.3 \%$ ) reported as other; ${ }^{\mathrm{g}} 15$ (10.7\%) patients had mixed membranoproliferative involvement 


\section{References}

1. Hanly JG, O'Keeffe AG, Su L, et al. The frequency and outcome of lupus nephritis: results from an international inception cohort study. Rheumatology (Oxford) 2016; 55: 252-62.

2. Cervera R, Khamashta MA, Font J, et al. Morbidity and mortality in systemic lupus erythematosus during a 10-year period: a comparison of early and late manifestations in a cohort of 1,000 patients. Medicine (Baltimore) 2003; 82: 299-308.

3. Bastian HM, Roseman JM, McGwin G, Jr., et al. Systemic lupus erythematosus in three ethnic groups. XII. Risk factors for lupus nephritis after diagnosis. Lupus 2002; 11: 152-60.

4. Pons-Estel BA, Catoggio LJ, Cardiel MH, et al. The GLADEL multinational Latin American prospective inception cohort of 1,214 patients with systemic lupus erythematosus: ethnic and disease heterogeneity among "Hispanics". Medicine (Baltimore) 2004; 83: 1-17.

5. Mok CC, Yap DY, Navarra SV, et al. Overview of lupus nephritis management guidelines and perspective from Asia. Int $J$ Rheum Dis 2013; 16: 625-36.

6. Tikly M, Navarra SV. Lupus in the developing world - is it any different? Best Pract Res Clin Rheumatol 2008; 22: 643-55.

7. Dhir V, Aggarwal A, Lawrence A, Agarwal V, Misra R. Long-term outcome of lupus nephritis in Asian Indians. Arthritis Care Res (Hoboken) 2012; 64: 713-20.

8. Ameh Ol, Kengne AP, Jayne D, et al. Standard of treatment and outcomes of adults with lupus nephritis in Africa: a systematic review. Lupus 2016.

9. Singh S, Zhou XJ, Ahn C, Saxena R. A retrospective analysis of clinical presentation of lupus nephritis. Am J Med Sci 2011; 342: 467-73.

10. Contreras G, Pardo V, Cely C, et al. Factors associated with poor outcomes in patients with lupus nephritis. Lupus 2005; 14: 890-5. 
11. Dooley MA, Hogan S, Jennette C, Falk R. Cyclophosphamide therapy for lupus nephritis: poor renal survival in black Americans. Glomerular Disease Collaborative Network. Kidney Int 1997; 51: 1188-95.

12. Houssiau FA, Vasconcelos C, D'Cruz D, et al. Immunosuppressive therapy in lupus nephritis: the Euro-Lupus Nephritis Trial, a randomized trial of lowdose versus high-dose intravenous cyclophosphamide. Arthritis Rheum 2002; 46: 2121-31.

13. Isenberg D, Appel GB, Contreras G, et al. Influence of race/ethnicity on response to lupus nephritis treatment: the ALMS study. Rheumatology (Oxford) 2010; 49: 128-40.

14. Appel GB, Contreras G, Dooley MA, et al. Mycophenolate mofetil versus cyclophosphamide for induction treatment of lupus nephritis. J Am Soc Nephrol 2009; 20: 1103-12.

15. Houssiau FA, D'Cruz D, Sangle S, et al. Azathioprine versus mycophenolate mofetil for long-term immunosuppression in lupus nephritis: results from the MAINTAIN Nephritis Trial. Ann Rheum Dis 2010; 69: 2083-9.

16. Hannah J, Casian A, D'Cruz D. Tacrolimus use in lupus nephritis: A systematic review and meta-analysis. Autoimmun Rev 2016; 15: 93-101.

17. Mok CC. Towards new avenues in the management of lupus glomerulonephritis. Nat Rev Rheumatol 2016; 12: 221-34.

18. Bao H, Liu ZH, Xie HL, Hu WX, Zhang HT, Li LS. Successful treatment of Class V+IV lupus nephritis with multitarget therapy. J Am Soc Nephrol 2008; 19: 2001-10.

19. Hahn BH, McMahon MA, Wilkinson A, et al. American College of Rheumatology guidelines for screening, treatment, and management of lupus nephritis. Arthritis Care Res (Hoboken) 2012; 64: 797-808.

20. Chan TM, Tse KC, Tang CS, Mok MY, Li FK. Long-term study of mycophenolate mofetil as continuous induction and maintenance treatment for diffuse proliferative lupus nephritis. J Am Soc Nephrol 2005; 16: 107684. 
21. Rovin BH, Parikh SV, Hebert LA, et al. Lupus nephritis: induction therapy in severe lupus nephritis - should MMF be considered the drug of choice? Clin J Am Soc Nephrol 2013; 8: 147-53.

22. Tan EM, Cohen AS, Fries JF, et al. The 1982 revised criteria for the classification of systemic lupus erythematosus. Arthritis Rheum 1982; 25: 1271-7.

23. Hochberg MC. Updating the American College of Rheumatology revised criteria for the classification of systemic lupus erythematosus. Arthritis Rheum 1997; 40: 1725.

24. Eckardt KU, Berns JS, Rocco MV, Kasiske BL. Definition and classification of CKD: the debate should be about patient prognosis - a position statement from KDOQI and KDIGO. Am J Kidney Dis 2009; 53: 915-20.

25. Levey AS, Coresh J, Greene T, et al. Using standardized serum creatinine values in the modification of diet in renal disease study equation for estimating glomerular filtration rate. Ann Intern Med 2006; 145: 247-54.

26. Churg J BJ, Glassock R. Lupus nephritis. Renal disease: Classification and Atlas of Renal Disease New York: Igaku-New Shoin, 1995, p. 151-5.

27. Alarcon GS, McGwin G, Jr., Bartolucci AA, et al. Systemic lupus erythematosus in three ethnic groups. IX. Differences in damage accrual. Arthritis Rheum 2001; 44: 2797-806.

28. Toloza SM, Uribe AG, McGwin G, Jr., et al. Systemic lupus erythematosus in a multiethnic US cohort (LUMINA). XXIII. Baseline predictors of vascular events. Arthritis Rheum 2004; 50: 3947-57.

29. Rivest C, Lew RA, Welsing PM, et al. Association between clinical factors, socioeconomic status, and organ damage in recent onset systemic lupus erythematosus. J Rheumatol 2000; 27: 680-4.

30. Cooper GS, Treadwell EL, St Clair EW, Gilkeson GS, Dooley MA. Sociodemographic associations with early disease damage in patients with systemic lupus erythematosus. Arthritis Rheum 2007; 57: 993-9. 
31. Patel M, Clarke AM, Bruce IN, Symmons DP. The prevalence and incidence of biopsy-proven lupus nephritis in the UK: Evidence of an ethnic gradient. Arthritis Rheum 2006; 54: 2963-9.

32. Borchers AT, Naguwa SM, Shoenfeld Y, Gershwin ME. The geoepidemiology of systemic lupus erythematosus. Autoimmun Rev 2010; 9: A277-87.

33. Wadee S, Tikly M, Hopley M. Causes and predictors of death in South Africans with systemic lupus erythematosus. Rheumatology 2007; 46: 148791.

34. Ayodele OE, Okpechi IG, Swanepoel CR. Predictors of poor renal outcome in patients with biopsy-proven lupus nephritis. Nephrology (Carlton) 2010; 15: 482-90.

35. Zheng ZH, Zhang LJ, Liu WX, et al. Predictors of survival in Chinese patients with lupus nephritis. Lupus 2012; 21: 1049-56.

36. Galindo-Izquierdo M, Rodriguez-Almaraz E, Pego-Reigosa JM, et al. Characterization of Patients With Lupus Nephritis Included in a Large Cohort From the Spanish Society of Rheumatology Registry of Patients With Systemic Lupus Erythematosus (RELESSER). Medicine (Baltimore) 2016; 95: e2891.

37. Rivera TL, Belmont HM, Malani S, et al. Current therapies for lupus nephritis in an ethnically heterogeneous cohort. J Rheumatol 2009; 36: 298-305.

38. Furness PN, Taub N. Interobserver reproducibility and application of the ISN/RPS classification of lupus nephritis-a UK-wide study. Am J Surg Pathol 2006; 30: 1030-5.

39. Kono M, Yasuda S, Kato M, et al. Long-term outcome in Japanese patients with lupus nephritis. Lupus 2014; 23: 1124-32.

40. Mahmoud GA, Zayed HS, Ghoniem SA. Renal outcomes among Egyptian lupus nephritis patients: a retrospective analysis of 135 cases from a single centre. Lupus 2015; 24: 331-8. 
41. Bhinder S, Singh A, Majithia V. Membranous (Class V) renal disease in systemic lupus erythematosus may be more common than previously reported: results of a 6-year retrospective analysis. Am J Med Sci 2010; 339: 230-2.

42. Seshan SV, Jennette JC. Renal disease in systemic lupus erythematosus with emphasis on classification of lupus glomerulonephritis: advances and implications. Arch Pathol Lab Med 2009; 133: 233-48.

43. Wen YK. Renal biopsy findings in new-onset systemic lupus erythematosus with clinical renal disease. Int Urol Nephrol 2011; 43: 801-6.

44. Illei GG, Austin HA, Crane $M$, et al. Combination therapy with pulse cyclophosphamide plus pulse methylprednisolone improves long-term renal outcome without adding toxicity in patients with lupus nephritis. Ann Intern Med 2001; 135: 248-57.

45. Chan TM, Li FK, Tang CS, et al. Efficacy of mycophenolate mofetil in patients with diffuse proliferative lupus nephritis. N Engl J Med 2000; 343: 1156-62.

46. Ginzler EM, Dooley MA, Aranow C, et al. Mycophenolate mofetil or intravenous cyclophosphamide for lupus nephritis. N Engl J Med 2005; 353: 2219-28.

47. Appel GB. New and future therapies for lupus nephritis. Cleve Clin J Med 2012; 79: 134-40.

48. Dooley MA, Jayne D, Ginzler EM, et al. Mycophenolate versus azathioprine as maintenance therapy for lupus nephritis. N Engl J Med 2011; 365: 188695.

49. Contreras G, Pardo V, Leclercq B, et al. Sequential Therapies for Proliferative Lupus Nephritis. N Engl J Med 2004; 350: 971-80.

50. Bertsias GK, Tektonidou M, Amoura Z, et al. Joint European League Against Rheumatism and European Renal Association-European Dialysis and Transplant Association (EULAR/ERA-EDTA) recommendations for the 
management of adult and paediatric lupus nephritis. Ann Rheum Dis 2012; 71: 1771-82.

51. Radhakrishnan J, Moutzouris DA, Ginzler EM, Solomons N, Siempos, II, Appel GB. Mycophenolate mofetil and intravenous cyclophosphamide are similar as induction therapy for Class V lupus nephritis. Kidney Int 2010; 77: 152-60.

52. Lu F, Tu Y, Peng X, et al. A prospective multicentre study of mycophenolate mofetil combined with prednisolone as induction therapy in 213 patients with active lupus nephritis. Lupus 2008; 17: 622-9.

53. Chan TM, Li FK, Tang CS, et al. Efficacy of mycophenolate mofetil in patients with diffuse proliferative lupus nephritis. Hong Kong-Guangzhou Nephrology Study Group. N Engl J Med 2000; 343: 1156-62.

54. Yap DY, Ma MK, Mok MM, Tang CS, Chan TM. Long-term data on corticosteroids and mycophenolate mofetil treatment in lupus nephritis. Rheumatology (Oxford) 2013; 52: 480-6.

55. Bono L, Cameron JS, Hicks JA. The very long-term prognosis and complications of lupus nephritis and its treatment. QJM 1999; 92: 211-8.

56. Haddiya I, Hamzaoui H, Tachfouti N, et al. Features and outcomes of lupus nephritis in Morocco: analysis of 114 patients. Int $J$ Nephrol Renovasc Dis 2013; 6: 249-58.

57. Khanfir MS, Houman MH, Cherif E, et al. TULUP (TUnisian LUPus): a multicentric study of systemic lupus erythematosus in Tunisia. Int $J$ Rheum Dis 2013; 16: 539-46.

58. Wang YF, Xu YX, Tan Y, Yu F, Zhao MH. Clinicopathological characteristics and outcomes of male lupus nephritis in China. Lupus 2012; 21: 1472-81.

59. Yokoyama $\mathrm{H}$, Okuyama $\mathrm{H}$, Yamaya $\mathrm{H}$. Clinicopathological insights into lupus glomerulonephritis in Japanese and Asians. Clin Exp Nephrol 2011; 15: 321-30. 
60. Cervera R, Khamashta MA, Font J, et al. Systemic lupus erythematosus: clinical and immunologic patterns of disease expression in a cohort of 1,000 patients. Medicine 1993; 72: 113-24.

61. Al Durahim H, Al Ghamdi G, Al Seraya A, Alkhiari R, Al Sayyari A. Predictors of mortality and end stage renal disease in Saudi patients with lupus nephritis. Lupus 2011; 20: 1329-35.

62. Shariati-Sarabi Z, Ranjbar A, Monzavi SM, Esmaily H, Farzadnia M, Zeraati AA. Analysis of clinicopathologic correlations in Iranian patients with lupus nephritis. Int J Rheum Dis 2013; 16: 731-8.

63. Contreras G, Lenz O, Pardo V, et al. Outcomes in African Americans and Hispanics with lupus nephritis. Kidney Int 2006; 69: 1846-51.

64. Rovin $\mathrm{BH}$, Furie $\mathrm{R}$, Latinis $\mathrm{K}$, et al. Efficacy and safety of rituximab in patients with active proliferative lupus nephritis: the Lupus Nephritis Assessment with Rituximab study. Arthritis Rheum 2012; 64: 1215-26. 


\section{Appendices}

Appendix 1: Study protocol

Appendix 2: Guidelines for Authorship for the journal LUPUS

Appendix 3: Ethics approval

Appendix 4: Data collection sheet

Appendix 5: Abbreviations 


\section{Appendix 1: The final Study Protocol}

RESEARCHER: Dr.Priyesh Girish Mody

CHIEF SUPERVISOR: Prof. A. Assounga (Dept. of Nephrology)

CO- SUPERVISOR: $\quad$ Prof. G.M. Mody (Dept. of Rheumatology)

CO-INVESTIGATORS: Prof. P.K. Ramdial (Dept of Anatomical Pathology)

Dr S. Haripershad (Dept. of Nephrology)

DEPARTMENT: Dept. of Nephrology - Inkosi Albert Luthuli Hospital

Dept. of Rheumatology - Inkosi Albert Luthuli Hospital

Title:

"The Severity and Outcome of Lupus Nephritis in Clinical Practice"

Type of Study:

Clinical

\section{The Project}

1. Aim:

The aim of the study is to review the records of all the patients with lupus nephritis seen at the Departments of Nephrology and Rheumatology at Inkosi Albert Luthuli Central Hospital to determine the severity and outcome:

Objectives:

Primary -

- The severity of lupus nephritis at the time of presentation based on the assessment of renal function and where possible, renal biopsy findings.

Secondary - 
- The correlation between the demographic data, clinical features and laboratory manifestations of systemic lupus erythematosus and comorbid diseases, and severity of lupus nephritis.

- The course and outcome of lupus nephritis in response to the various modalities of therapy

2. Hypothesis:

- The primary objective is a descriptive retrospective analysis of the records of patients with lupus nephritis to determine the severity of lupus nephritis at presentation and the outcome in response to the various treatment modalities. No specific hypothesis will be tested for this objective.

- The secondary objective is to assess the response of patients with lupus nephritis treated with corticosteroids and either mycophenolate mofetil as initial and maintenance therapy versus those who were treated with conventional induction therapy with cyclophosphamide followed by azathioprine maintenance therapy. Therefore, the secondary hypothesis is that the different treatment protocols affects disease outcome with regards to its morbidity.

\section{Background and Literature}

Systemic lupus erythematosus (SLE) is an autoimmune connective tissue disease which is characterised by multisystem involvement. The diagnosis of SLE is based on the American College of Rheumatology (ACR) criteria for the classification of SLE (Appendix 1) The common presenting features are cutaneous and musculoskeletal and the most serious manifestations are involvement of the kidneys, heart and central nervous system.

There has been a marked improvement in the survival of patients with SLE with a 5 year survival of over $90 \%$ being reported in industrialized countries ${ }^{[1]}$ compared to a 5 year survival of $40 \%$ reported in $1956{ }^{[2]}$. In developing countries, SLE patients have a high morbidity and mortality and 5 -year survival rates have been estimated at between $57 \%$ and $72 \%$ in South Africa ${ }^{[3]}$. 
The manifestations of lupus nephritis are related to the presence of hypertension, nephrotic syndrome and renal failure. Lupus nephritis is one of the more severe organ manifestations of SLE (occurring in up to $60 \%$ of adult SLE patients) and is associated with a high morbidity and mortality ${ }^{[4]}$. The 5 -year survival in patients with lupus nephritis was close to zero during the 1950s. The use of intensive immunosuppressive therapy with cyclophosphamide together with the availability of better antibiotics, intensive care facilities, dialysis and transplantation has resulted in 5 - year survival rates as high as $85 \%$ and 10 - year survival rates of $73 \%{ }^{[5]}$. In patients with SLE, lupus nephritis has been shown to be associated with a much lower 5 - year survival rate when compared to patients without nephritis $(60 \%$ vs. $84 \%)^{[1]}$.

In clinical practice a decision to perform a renal biopsy is taken by the attending physician based on the presence of urinary abnormalities such as the presence of protein, blood or casts in the urine, a rise in the urea and creatinine and reduced creatinine clearance or glomerular filtration rate.

The renal histology has been classified using the 1995 modification of the World Health Organization Classification of lupus nephritis. In newer studies the histopathological findings on renal biopsy are classified according to the International Society of Nephrology / Renal Pathology Society 2003 classification of lupus nephritis based on the morphological changes in the glomerulus and tubulointerstitium. Patients are classified as class 1 to class 6 depending on the histopathological changes (Appendix 2). In addition, the activity and chronicity scores can be assessed to determine the possibility of response to therapy and therefore provide a guide to the use of immunosuppressive therapy (Appendix 3).

A 2004 study by Weening et al (2004) ${ }^{[6]}$ showed that the milder Class II and Class IIla lupus nephritis affected $35 \%$ to $50 \%$ of patients, whereas more severe lupus nephritis, Class IIIb, IV, and V occurred in $45 \%$ to $60 \%$ of patients. Some patients with Class III disease (focal segmental proliferative GN) may deteriorate and progress to Class IV (diffuse proliferative GN). Patients with Class IV disease usually present with impaired renal function. Patients with Class $V$ disease may present with nephrotic syndrome. 
A Chinese study of 86 patients with lupus nephritis reported clinical remission with normal renal function in 47 patients (55\%), stable renal function in 11 patients (13\%) and end stage renal disease developed in 28 patients $(32 \%)^{[7]}$.

A previous retrospective study of 51 patients with lupus nephritis at Tygerberg hospital in Cape Town in 1991 noted that the majority of the patients had severe renal disease at the time of biopsy and that $19 / 51(37 \%)$ of the patients died ${ }^{[8]}$. The poor prognostic factors were the serum creatinine and creatinine clearance at the time of biopsy or follow up, the presence of hypertension and severity of histological changes.

Current therapeutic recommendations for the treatment of lupus nephritis include a 6 month induction phase with corticosteroids and either cyclophosphamide or mycophenolate mofetil to suppress the host-mediated immune response and prevent disease progression and fibrosis. The induction phase is generally followed by a long-term maintenance phase with azathioprine or mycophenolate mofetil to prevent relapses or recurrence.

Traditionally, intravenous cyclophosphamide has been used as the cytotoxic drug of choice to halt disease progression in proliferative lupus nephritis, based on the recommendations of the US National Institute of Health $(\mathrm{NIH})$ trial of $1986{ }^{[9]}$. The renal benefits of cyclophosphamide are often countered by severe systemic side effects such as gonadal toxicity, haemorrhagic cystitis, bone marrow suppression, and an increased risk of malignancy. Azathioprine has been used as the maintenance drug after completion of the 6-month induction phase with cyclophosphamide. The EURO-LUPUS Nephritis Trial showed that the use of a lower dose of cyclophosphamide given at a more frequent interval provided adequate immunosuppression and was associated with a lower prevalence of side effects ${ }^{[10]}$.

Mycophenolic acid, the active metabolite of mycophenolate mofetil (MMF, Cellcept ${ }^{\circledR}$ ), selectively suppresses the proliferation of $\mathrm{T}$ and $\mathrm{B}$ cells, the formation of antibodies and the glycosylation of adhesion molecules by inhibiting de novo purine nucleotide synthesis and depleting granulocytes of guanosine triphosphate ${ }^{[11]}$. MMF is registered for use as an immunosuppressant in transplant recipients, and was 
initially only used as an alternative agent in patients who are resistant to or experience adverse effects with cyclophosphamide.

The Aspreva Pharmaceuticals study found relatively equivalent efficacy rates between cyclophosphamide and MMF during a 24 week induction phase [12]. Similarly, Chan et al found comparable results during a 12 month study of 42 patients with Class IV lupus nephritis but noted there was greater tolerability with MMF [13].

A 2005 prospective controlled study by Ginzler et $a{ }^{[14]}$ has shown that the use of MMF in combination with glucocorticosteroids as induction therapy, is more effective than the traditional regimens (52\% vs. $30 \%$ respectively), and is associated with fewer side effects. However, this study population comprised of $56 \%$ AfricanAmerican, and the dose of MMF used was $3 g$ per day.

In 2008, a retrospective study of all SLE patients comprising a multiethnic population seen at New York University Medical Centre, found that the response to MMF was superior to cyclophosphamide (71\% vs. $40 \%$ respectively) during the induction phase. Response to MMF was greatest amongst Asians, with Hispanics accounting for majority of non-responders, a finding consistent with previous studies [15]. In this study, there was no statistically significant difference between MMF and cyclophosphamide during the maintenance phase.

A 2004 study by Contreras et al found a significantly higher rate of treatment failure (death or chronic renal failure) with mycophenolate mofetil than with cyclophosphamide ${ }^{[16]}$. Chan et al. found an increased rate of disease flares with low dose mycophenolate mofetil as compared with azathioprine in a long-term follow-up study (median, 63 months) ${ }^{[17]}$.

\section{Summary of proposed research:}

\section{STUDY DESIGN.}

The records of the patients seen in the Departments of Nephrology and Rheumatology from January 2003 to December 2012 will be reviewed to identify patients with a diagnosis of lupus nephritis. Patients who received treatment for a period of at least 6 months will be selected for inclusion in the study. 
The hospital records of all the patients will be analysed and the following information will be recorded.

1. Demographic data to include age at time of biopsy, ethnic group, gender, and duration of disease.

2. The presence of the ACR classification criteria and other clinical manifestations of SLE in the past and at the time of diagnosis of lupus nephritis.

3. The results of laboratory investigations to include full blood count, liver function tests, erythrocyte sedimentation rate, C-reactive protein, antibody tests such as the anti-nuclear factor, anti-dsDNA antibodies, extractable nuclear antigens, anti-phospholipid antibodies, serum complement and other investigations such as chest $x$-ray findings, blood cultures etc where clinically indicated.

4. Assessment of the kidneys based on urine microscopy and chemistry, serum urea and creatinine, creatinine clearance rate and glomerular filtration rate, $24 \mathrm{hr}$ urine protein excretion, ultrasound of the kidneys and renal biopsy assessment of the class of lupus nephritis.

5. The presence of co-morbid conditions such as hypertension, ischaemic heart disease, dyslipidaemia and diabetes, complications such as the presence of infections and any adverse effects of therapy

6. The treatment regimen for the management of lupus nephritis such as steroids, cyclophosphamide, azathioprine, mycophenolate mofetil, renal dialysis and or renal transplantation

7. Definition of outcomes:

A) The definition of outcomes has varied in different studies but similar variables are used to determine the outcome. In order to compare our findings with other studies on lupus nephritis we chose the following definitions:

Responders:

Patients were stratified as responders if they had a complete or partial remission. A complete remission was defined as a reduction in the proteinuria to $<0.5 \mathrm{~g} / 24$ hours with a normal serum creatinine. A partial remission was defined as a reduction in proteinuria to $<3 \mathrm{~g} / 24$ hours if it was in the nephrotic 
range or a reduction by more than $50 \%$ if it was in the sub-nephrotic range, accompanied by stabilization of the serum creatinine to $\pm 25 \%$ of the baseline value or an improvement in the serum creatinine.

Non-responders

Patients who failed to show a response, had deterioration of renal function, required renal replacement therapy, were lost to follow up or died were classified as non-responders

B) For those patients who fail to respond, the eventual outcome will be recorded as to whether they maintained stable renal function or there was progression to end-stage renal failure requiring dialysis or transplantation, or death.

C) The response to therapy will be assessed after 6 months of induction therapy and 12 months' maintenance therapy.

\section{INCLUSION CRITERIA}

1) All the patients who have a clinico-pathological diagnosis of lupus nephritis will be included in the study. Patients with SLE with renal involvement in whom a renal biopsy could not be performed will be recorded separately. The latter group will include severely ill patients with multisystem involvement, patients with whom a renal biopsy was contraindicated due to severe disease activity or abnormal bleeding parameters, or where a biopsy could not be performed for technical reasons. These patients will be classified as having SLE or incomplete SLE depending on whether they fulfill the ACR classification criteria for SLE.

\section{EXCLUSION CRITERIA}

1) Patients with lupus nephritis who did not receive treatment for a period of at least 6 months or who were lost to follow up before completing at least 6 months' treatment.

2) Patients whose biopsies suggested multiple pathology.

\section{POPULATION}


The study sample will be identified from a review of the records of patients with SLE seen in the Departments of Nephrology and Rheumatology in whom a diagnosis of lupus nephritis was made based on their clinical presentation, laboratory findings and / or renal histology.

There are some patients who have severe SLE with renal involvement in whom a renal biopsy was not performed due to them having a bleeding disorder or being severely ill. These patients will be recorded separately to avoid a bias of excluding severely ill patients who may have had a poorer outcome.

\section{SAMPLING}

The patients who will be included in the study will be selected from a chart review of the records of patients with SLE seen in the Departments of Nephrology and Rheumatology during the period January 2003 to December 2012. This will reduce the chance of patients with lupus nephritis being omitted based only on a review of the clinical records alone.

\section{STATISTICAL PLANNING}

Data from the identified records will be transcribed onto a Data Collection form (Appendix 4). Data will be coded and captured appropriately according to statistical requirements onto an EXCEL spreadsheet. This will be imported into SPSS for analysis.

SPSS version 15.0 (SPSS Inc., Chicago, Illinois, USA) computer based statistical software will be used for data analysis

\section{SAMPLE SIZE}

The sample size will depend on the number of patients with histologically proven lupus nephritis or a clinical diagnosis of lupus nephritis seen in the Departments of Nephrology and Rheumatology seen during the study period. Since the primary objective of this study is purely descriptive, no sample size calculations were performed. The secondary objective will be tested statistically using hypothesis testing, but in the event that the sample is insufficient, statistical power trends and absolute differentials will be reported and commented on rather that statistical significance. 


\section{DATA COLLECTION}

Data will be obtained from the computerised patient database at IALCH and entered into a data collection sheet for analysis.

\section{DATA ANALYSIS TECHNIQUES}

All categorical variables will be summarised as counts and percentages. Numerical variables will be summarised as measures of central location (mean / median) and dispersion (standard deviation / interquartile range). Pearson's chi square tests and independent sample t-tests will be used in bivariate analysis to assess factors associated with non-response. Logistic regression analysis will be used to assess the risk factors associated with non-response after controlling for confounding variables such as initial disease severity. The statistical tests have been determined based on the advice of a statistician.

\section{STUDY LOCATION}

IALCH in Durban, Kwa Zulu-Natal, South Africa

\section{STUDY PERIOD}

The study period will be from January 2003 to December 2012.

The study is due for completion by December 2016 .

\section{LIMITATIONS:}

1) In view of this study being a retrospective chart review, there may be some investigations which may not have been performed at the time of the diagnosis of lupus nephritis.

2) The decision to perform a renal biopsy is dependent on the decision of the managing physician. Thus it is possible that some patients may have received treatment based on assessment of the clinical findings and laboratory tests without having a renal biopsy.

3) The exclusion of patients with dual or multiple renal pathologies may result in some patients with lupus nephritis being excluded from the study due to the difficulty in determining their contribution to the renal pathology. 
4) The choice of immunosuppressive therapy is dependent on the preference of the managing physician. There may be a bias towards using the conventional induction regime with intravenous cyclophosphamide rather than MMF in patients with more severe renal disease.

5) The number of patients seen during the study period is predetermined and cannot be adjusted.

\section{ETHICAL CONSIDERATIONS:}

The identity of the participants will be withheld and only the hospital numbers and study numbers will be used to identify participants.

There will be no direct patient participation.

\section{Keywords}

"Lupus Nephritis" "Cyclophosphamide" and "mycophenolate mofetil”

\section{Key References}

1 Cervera R, Khamashta MA, Font J, et al. Morbidity and mortality in systemic lupus erythematosus during a 5-yr period. A multicenter prospective study of 1,000 patients. Medicine 2003; 82: 299-308.

2 Doria A, laccarino L, Ghiradello A, et al. Long-term prognosis and causes of death in systemic lupus erythematosus. Am J Med 2006; 119: 700-6

3 Wadee S, Tikly M, Hopley M. Causes and Predictors of death in South Africans with systemic lupus erythematosus Rheumatology 2007; 46: 148791.

4 Waldman M, Appe/ GB. Update on the treatment of lupus nephritis. Kidney Int. 2006; 70: 1403-1412.

5 Dooley MA. Clinicaland laboratory features of lupus nephritis. In:

Wallace DJ, Hahn BH, eds. Dubois' Lupus Erythematosus. $7^{\text {th }}$ ed. Philadelphia, PA: Lippincott Williams \& Wilkins; 2007: 1112-30. 
6 Weening JJ, D'Agati VD, Schwartz MM, et al. The classification of glomerulonephritis in systemic lupus erythematosus revisited. J Am Soc Nephrol 2004; 15: 241- 250.

7 Shen K, Yu Y, Tang Z, Liu Z, Li L. Chin. The prognosis of biopsy proven lupus nephritis in Chinese patients: long term follow-up of 86 patients. Chin Med J (Engl). 1997 Jul; 110(7): 502-7.

8 W.D. Bates, A.M. Halland, R.D. Tribe, D.J. Rossouw. Lupus Nephritis Part I Histopathological classification, activity and chronicity scores. S AFR MED J 1991; 79: $256-9$.

9 Austin HA III, Kippel JH, Barlow JE, et al. Therapy of lupus nephritis. controlled trial of prednisone and cytotoxic drugs. N Engl J Med 1986; 314: $614-9$.

10 Houssiau FA, Vasconcelos C, D'Cruz D, et al. Early response to immunosuppressive therapy predicts good renal outcome in lupus nephritis: lessons from long-term follow-up of patients in the Euro-Lupus Nephritis Trial. Arthritis Rheum 2004; 50: 3934 - 40.

11 Allison AC, Eugui EM. Purine metabolism and immunosuppressive effects of mycophenolate mofetil (MMF). Clin Transplan 1996; 10: 77 - 84.

12 Gerald B. Appel, Gabriel Contreras, Mary Anne Dooley, et al. (Aspreva Lupus Management Study Group) Mycophenolate Mofetil versus Cyclophosphamide for Induction Treatment of Lupus Nephritis. J Am Soc Nephrol 2009; 20: $1103-1112$

13 Chan TM, Li FK, Tang CSO, et al. Efficacy of Mycophenolate mofetil in patients with diffuse proliferative lupus nephritis Chin Med $J$ (Engl) 2002;115:705-9.

14 Ellen M. Ginzler, M.D., M.P.H. Mycophenolate Mofetil or Intravenous Cyclophosphamide for Lupus Nephritis N Engl J Med 2005; 353: 2219 - 2228. 
15 Tania L, Rivera H, Micheal Bemont, Seema Malani, et al. Current therapies for Lupus Nephritis in an ethically Heterogenous Cohort. J Rheumatol 2009; 36: $298-304$.

16 Contreras G, Pardo V, Leclercq B, et al. Sequential therapies for proliferative lupus nephritis. N Engl J Med 2004; 350: 971-80.

17 Chan TM, Wong WS, Lau CS, et al. Follow-up of patients with diffuse proliferative lupus nephritis treated with prednisolone and mycophenolate mofetil. J Am Soc Nephrol 2001; 12: 195A. Abstract. 
APPENDIX 1

\section{Criterion Definition}

Malar rash

Discoid rash

Photosensitivity

Oral ulcers

Arthritis

Serositis

Renal

Neurologic

Hematologic

Immunologic
ACR criteria for diagnosis of systemic lupus erythematosus

Fixed erythema, flat or raised, over the malar eminences, tending to spare the nasolabial folds

Erythematosus raised patches with adherent keratotic scaling and follicular plugging; atrophic scarring may occur in older lesions

Skin rash as a result of unusual reaction to sunlight, by patient history or physician observation

Oral or nasopharyngeal ulceration, usually painless, observed by a physician

Non-erosive arthritis involving 2 or more peripheral joints, characterized by tenderness, swelling, or effusion

Pleuritis - convincing history of pleuritic pain or rub heard by a physician or evidence of pleural effusion OR

Pericarditis - documented by ECG, rub or evidence of pericardial effusion

Persistent proteinuria greater than 0.5 grams per day or greater than 3+ if quantitation not performed OR

Cellular casts - may be red cell, hemoglobin, granular, tubular, or mixed

Seizures OR psychosis - in the absence of offending drugs or known metabolic derangements (uremia, ketoacidosis, or electrolyte imbalance)

Haemolytic anemia - with reticulocytosis OR

Leukopenia - less than $4,000 / \mathrm{mm} 3$ total on two or more occasions OR

Lymphopenia - less than $1,500 / \mathrm{mm} 3$ on two or more occasions OR

Thrombocytopenia - less than $100,000 / \mathrm{mm} 3$ in the absence of offending drugs

Positive antiphospholipid antibody OR

Anti-dsDNA - antibody to native DNA in abnormal titre OR

Anti-Sm - presence of antibody to Sm nuclear antigen OR 
False positive serologic test for syphilis known to be positive for at least six months and confirmed by Treponema pallidum immobilization or fluorescent treponemal antibody absorption test

Antinuclear factor An abnormal titre of antinuclear antibody by immunofluorescence or an equivalent assay at any point in time and in the absence of drugs known to be associated with "drug-induced lupus" syndrome 


\section{APPENDIX 2 International Society of Nephrology/Renal Pathology Society (ISN/RPS) 2003 Classification of Lupus Nephritis}

\begin{tabular}{|c|c|c|}
\hline \multirow{3}{*}{$\begin{array}{l}\text { Class I } \\
\text { Minimal mesangial lupus nephritis }\end{array}$} & LM findings & Normal \\
\hline & IF/EM findings & Mesangial immune deposits \\
\hline & Clinical manifestations & Mild proteinuria \\
\hline \multirow[t]{3}{*}{$\begin{array}{l}\text { Class II } \\
\text { Mesangial proliferative lupus nephritis }\end{array}$} & LM findings & $\begin{array}{l}\text { Purely mesangial hypercellularity or mesangial matrix expansion with mesangial } \\
\text { immune deposits }\end{array}$ \\
\hline & IF/EM findings & $\begin{array}{l}\text { Mesangial immune deposits; few immune deposits in subepithelial or subendothelial } \\
\text { deposits possible }\end{array}$ \\
\hline & Clinical manifestations & $\begin{array}{l}\text { These patients have mild renal disease such as asymptomatic haematuria or } \\
\text { proteinuria that usually does not warrant specific therapy. }\end{array}$ \\
\hline \multirow{3}{*}{$\begin{array}{l}\text { Class III } \\
\text { Focal lupus nephritis } \\
\text { Class III (A) } \\
\text { Active lesions: focal proliferative lupus nephritis } \\
\text { Class III (A/C) } \\
\text { Active and chronic lesions: focal proliferative and } \\
\text { sclerosing lupus nephritis } \\
\text { Class III (C) } \\
\text { Chronic inactive lesions: focal sclerosing lupus nephritis }\end{array}$} & LM findings & $\begin{array}{l}\text { Active or inactive focal, segmental, or global glomerulonephritis involving }<50 \% \text { of all } \\
\text { glomeruli }\end{array}$ \\
\hline & IF/EM findings & Subendothelial and mesangial immune deposits \\
\hline & Clinical manifestations & $\begin{array}{l}\text { Many patients present with active generalized SLE and mild-to-moderate renal } \\
\text { disease with haematuria and moderate proteinuria; significant minority show } \\
\text { worsening renal function and may progress to Class IV lupus nephritis. }\end{array}$ \\
\hline \multirow{2}{*}{$\begin{array}{l}\text { Class IV } \\
\text { Diffuse lupus nephritis } \\
\text { Class IV-S (A) } \\
\text { Active lesions: Diffuse segmental proliferative lupus } \\
\text { nephritis } \\
\text { Class IV-G (A) } \\
\text { Active lesions: Diffuse global proliferative lupus nephritis }\end{array}$} & LM findings & $\begin{array}{l}\text { Active or inactive diffuse, segmental or global glomerulonephritis involving } \geq 50 \% \text { of } \\
\text { all glomeruli; subdivided into diffuse segmental (Class IV-S) when } \geq 50 \% \text { of involved } \\
\text { glomeruli have segmental lesions (involving less than half of glomerular tuft) and } \\
\text { diffuse global (Class IV-G) when } \geq 50 \% \text { of involved glomeruli have global lesions }\end{array}$ \\
\hline & IF/EM findings & Subendothelial immune deposits \\
\hline $\begin{array}{l}\text { Class IV-S }(A / C) \\
\text { Active and chronic lesions: diffuse global proliferative and } \\
\text { sclerosing lupus nephritis } \\
\text { Class IV-S }(C) \\
\text { Chronic inactive lesions: diffuse segmental sclerosing } \\
\text { lupus nephritis } \\
\text { Class IV-G (C) } \\
\text { Chronic inactive lesions: Diffuse global sclerosing lupus } \\
\text { nephritis }\end{array}$ & Clinical manifestations & $\begin{array}{l}\text { These patients usually present with clinical evidence of renal disease including } \\
\text { hypertension, edema, active urinary sediment, worsening renal function, and } \\
\text { nephrotic range proteinuria is present; these patients often have active extrarenal } \\
\text { SLE. }\end{array}$ \\
\hline
\end{tabular}




\begin{tabular}{|c|c|c|}
\hline \multirow[t]{3}{*}{$\begin{array}{l}\text { Class V } \\
\text { Membranous lupus nephritis }\end{array}$} & LM findings & $\begin{array}{l}\text { Diffuse thickening of glomerular basement membrane without inflammatory infiltrate; } \\
\text { possibly, subepithelial deposits and surrounding basement membrane spikes on } \\
\text { special stains, including silver and trichrome; may occur in combination with Class II } \\
\text { or IV; may show advanced sclerosis }\end{array}$ \\
\hline & IF/EM findings & $\begin{array}{l}\text { Subepithelial and intramembranous immune deposits; subendothelial deposits } \\
\text { present only when associated proliferative component is present }\end{array}$ \\
\hline & Clinical manifestations & $\begin{array}{l}\text { These patients have clinical and laboratory features of nephrotic syndrome, usually } \\
\text { without manifestations of active SLE. }\end{array}$ \\
\hline \multirow[t]{2}{*}{$\begin{array}{l}\text { Class VI } \\
\text { Advanced sclerosis lupus nephritis }\end{array}$} & LM findings & $\begin{array}{l}\text { Advanced glomerular sclerosis involving } \geq 90 \% \text { of glomeruli, interstitial fibrosis, and } \\
\text { tubular atrophy, all morphological manifestations of irreversible renal injury }\end{array}$ \\
\hline & Clinical manifestations & $\begin{array}{l}\text { These patients usually have significant renal insufficiency or end-stage renal disease } \\
\text { and are unlikely to respond to medical therapy. }\end{array}$ \\
\hline
\end{tabular}


APPENDIX 3 Active and Chronic Glomerular Lesions

\begin{tabular}{||l|l|}
\hline \multicolumn{1}{|c|}{ Activity Index } & \multicolumn{1}{|c|}{ Chronicity Index } \\
\hline - Endocapillaryhypercellularity with or without leukocyte infiltration; luminal & $\begin{array}{l}\text { • Glomerular sclerosis; segmental, global } \\
\text { - Fibrous adhesion } \\
\text { reduction }\end{array}$ \\
- Karyorrhexis & - Fibrous crescents \\
- Fibrinoid necrosis \\
- Rupture of glomerular basement membrane \\
- Cellular or fibrocellular crescents \\
- Subendothelial deposits on light microscopy \\
- Intraluminal immune aggregates
\end{tabular}




\section{Appendix 2: The Guidelines for Authorship for the Journal LUPUS}

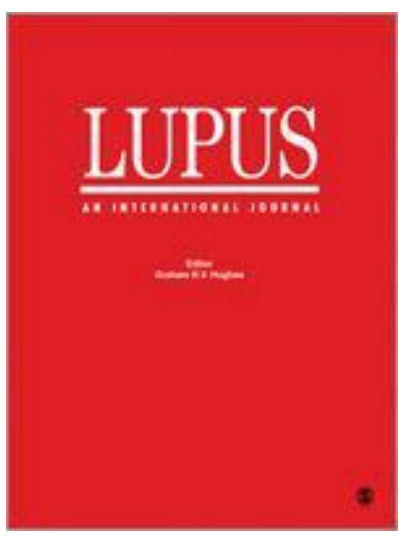

\section{Lupus}

An International Journal

2015 Impact Factor: 2.118

2015 Ranking: 19/32 in Rheumatology

2016 Release of Journal Citation Reports, Source: 2015 Web of Science

Data

Editor-in-Chief

Graham R V HughesKing's College London, UK

\section{Associate Editors}

M. KhamashtaSt Thomas' Hospital, UK

Robert LahitaNewark Beth Israel Medical Center, USA

\section{- $\quad$ SUBMISSION GUIDELINES}

1. Article types

2. Editorial Policies

2.1 Peer review policy

2.2 Authorship

2.3 Acknowledgments

2.4 Funding

2.5 Declaration of conflicting interests

2.6 Research ethics and patient consent

2.7 Clinical Trials

2.8 Reporting Guidelines

2.9 Data

3. Publishing Policies

3.1 Publication Ethics

3.2 Contributor's publishing agreement

3.3 Open Access and author archiving

3.4 Permissions

4. Preparing your manuscript

4.1 Word processing formats

4.2 Artwork, figures and other graphics

4.3 Supplementary material

4.4 Journal layout

4.5 Reference style

4.6 English language editing services

5. Submitting your manuscript

5.1 How to submit your manuscript

5.2 Title, keywords and abstracts

5.3 Corresponding author contact details

6. On acceptance and publication

6.1 SAGE Production

6.2 Access to your published article

6.3 Online First publication

7. Further Information

This Journal is a member of the Committee on Publication Ethics

This Journal recommends that authors follow the Uniform Requirements for Manuscripts 
Submitted to Biomedical Journals formulated by the International Committee of Medical Journal Editors (ICMJE)

There are no fees payable to submit or publish in this journal.

Please read the guidelines below then visit the Journal's submission site http:/mc.manuscriptcentral.com/lupus to upload your manuscript. Please note that manuscripts not conforming to these guidelines may be returned.

Only manuscripts of sufficient quality that meet the aims and scope of Lupus will be reviewed.

As part of the submission process you will be required to warrant that you are submitting your original work, that you have the rights in the work, that you are submitting the work for first publication in the Journal and that it is not being considered for publication elsewhere and has not already been published elsewhere, and that you have obtained and can supply all necessary permissions for the reproduction of any copyright works not owned by you.

\section{Article types}

Lupus is published fourteen times a year. The Editor will consider for publication all suitable papers dealing directly or indirectly with lupus or related diseases. The journal publishes both clinical and non-clinical research papers. Original research articles should be limited to no more than 4,000 words, 50 references and 6 tables and/or figures. They will be peer reviewed by two referees. In addition to original papers, the journal also publishes editorials, reports, and letters.

EDITORIALS

Editorials are solicited by the Editor but suggestions for such material will be very welcome.

\section{GRAND ROUNDS CASES}

The purpose of a grand rounds submission is to educate the reader about one or more facets related to the disease lupus or of an autoimmune disease which is related to lupus. A clinicopathological conference can be submitted but this must have postmortem data and is usually a death conference or mortality conference.

Avoid extraneous material which has little bearing on the case at hand. The readers wish to learn about every facet of the case presented and not about other unrelated material.

The submitted case should contain:

Introduction - This should be no more than one or two short paragraphs and summarise what is about to be presented and the reasons why the case was chosen.

Case Presentation - This part contains a succinct narrative of the case itself. Figures, photographs and tables with data are welcome. Also encouraged are data on biopsies with illustrative materials if possible.

Discussion - The discussion should be a focused presentation of theory and/or pathogenetic data regarding the case.

Final Diagnosis - This should be only one sentence which gives the final diagnosis.

\section{CONCISE REPORTS}

These should be short investigative papers and reports organised in the same way as fulllength manuscripts but which contain 2000 words or less, with no more than 3 figures or tables and up to 15 references.

\section{CASE REPORTS}

The Editor will consider for publication case reports that illustrate points not previously reported in the literature. They should not exceed two printed pages in length. The number of references should not exceed ten.

The number of case reports published will be strictly limited. 
LETTERS TO THE EDITOR

Letters to the Editor are encouraged. They may deal with material in published papers or they may raise new issues. Short clinical or laboratory observations may also be presented as Letters.

Letters must contain no more than 500 words, 10 references, 1 table and/or 1 illustration. An abstract is not required and letters should not be divided into sections. Instructions for references, tables and figures are the same as for full length articles.

\section{SUPPLEMENTS}

The journal welcomes the opportunity of publishing supplements to regular issues of significant symposia providing the material represents original work not previously published. Sponsored symposia should be fully discussed with the Editor prior to agreement to publish. Faculty, subject matter and editorial content are all subject to the approval of the editorial office and the journal's integrity and reputation should in no way be compromised.

\section{Editorial policies}

\subsection{Peer review policy}

The journal's policy is to obtain at least two independent reviews of each article. Lupus operates a conventional single-blind reviewing policy in which the reviewer's name is always concealed from the submitting author. Referees will be encouraged to provide substantive, constructive reviews that provide suggestions for improving the work and distinguish between mandatory and non-mandatory recommendations. All manuscripts accepted for publication are subject to editing for presentation, style and grammar. Any major redrafting is agreed with the author but the Editor's decision on the text is final.

As part of the submission process you will be asked to provide the names of $X$ peers who could be called upon to review your manuscript. Recommended reviewers should be experts in their fields and should be able to provide an objective assessment of the manuscript. Please be aware of any conflicts of interest when recommending reviewers. Examples of conflicts of interest include (but are not limited to) the below:

- The reviewer should have no prior knowledge of your submission

- The reviewer should not have recently collaborated with any of the authors

- Reviewer nominees from the same institution as any of the authors are not permitted

Please note that the Editors are not obliged to invite any recommended/opposed reviewers to assess your manuscript.

\subsection{Authorship}

Papers should only be submitted for consideration once consent is given by all contributing authors. Those submitting papers should carefully check that all those whose work contributed to the paper are acknowledged as contributing authors.

The list of authors should include all those who can legitimately claim authorship. This is all those who:

1. Made a substantial contribution to the concept and design, acquisition of data or analysis and interpretation of data,

2. Drafted the article or revised it critically for important intellectual content,

3. Approved the version to be published.

Authors should meet the conditions of all of the points above. Each author should have participated sufficiently in the work to take public responsibility for appropriate portions of the content.

When a large, multicentre group has conducted the work, the group should identify the individuals who accept direct responsibility for the manuscript. These individuals should fully meet the criteria for authorship. 
Acquisition of funding, collection of data, or general supervision of the research group alone does not constitute authorship, although all contributors who do not meet the criteria for authorship should be listed in the Acknowledgments section. Please refer to the International Committee of Medical Journal Editors (ICMJE) authorship guidelines for more information on authorship.

\subsection{Acknowledgements}

All contributors who do not meet the criteria for authorship should be listed in an Acknowledgements section. Examples of those who might be acknowledged include a person who provided purely technical help, or a department chair who provided only general support.

\subsubsection{Writing Assistance}

Individuals who provided writing assistance, e.g. from a specialist communications company, do not qualify as authors and so should be included in the Acknowledgements section. Authors must disclose any writing assistance - including the individual's name, company and level of input - and identify the entity that paid for this assistance. It is not necessary to disclose use of language polishing services.

Any acknowledgements should appear first at the end of your article prior to your Declaration of Conflicting Interests (if applicable), any notes and your References.

\subsection{Funding}

Lupus requires all authors to acknowledge their funding in a consistent fashion under a separate heading. Please visit the Funding Acknowledgements page on the SAGE Journal Author Gateway to confirm the format of the acknowledgment text in the event of funding, or state that: This research received no specific grant from any funding agency in the public, commercial, or not-for-profit sectors.

\subsection{Declaration of conflicting interests}

It is the policy of Lupus to require a declaration of conflicting interests from all authors enabling a statement to be carried within the paginated pages of all published articles. Please ensure that a 'Declaration of Conflicting Interests' statement is included at the end of your manuscript, after any acknowledgements and prior to the references. If no conflict exists, please state that 'The Author(s) declare(s) that there is no conflict of interest'.

For guidance on conflict of interest statements, please see the ICMJE recommendations here

\subsection{Research ethics and patient consent}

Medical research involving human subjects must be conducted according to the World Medical Association Declaration of Helsinki

Submitted manuscripts should conform to the ICMJE Recommendations for the Conduct, Reporting, Editing, and Publication of Scholarly Work in Medical Journals, and all papers reporting animal and/or human studies must state in the methods section that the relevant Ethics Committee or Institutional Review Board provided (or waived) approval. Please ensure that you have provided the full name and institution of the review committee, in addition to the approval number.

For research articles, authors are also required to state in the methods section whether participants provided informed consent and whether the consent was written or verbal.

Information on informed consent to report individual cases or case series should be included in the manuscript text. A statement is required regarding whether written informed consent 
for patient information and images to be published was provided by the patient(s) or a legally authorized representative.

Please also refer to the ICMJE Recommendations for the Protection of Research Participants

All research involving animals submitted for publication must be approved by an ethics committee with oversight of the facility in which the studies were conducted.

\subsection{Clinical trials}

Lupus conforms to the ICMJE requirement that clinical trials are registered in a WHOapproved public trials registry at or before the time of first patient enrolment as a condition of consideration for publication. The trial registry name and $U R L$, and registration number must be included at the end of the abstract.

\subsection{Reporting guidelines}

The relevant EQUATOR Network reporting guidelines should be followed depending on the type of study. For example, all randomized controlled trials submitted for publication should include a completed Consolidated Standards of Reporting Trials (CONSORT) flow chart as a cited figure, and a completed CONSORT checklist as a supplementary file.

Other resources can be found at NLM's Research Reporting Guidelines and Initiatives

\subsection{Data}

SAGE acknowledges the importance of research data availability as an integral part of the research and verification process for academic journal articles.

Lupus requests all authors submitting any primary data used in their research articles ["alongside their article submissions" or "if the articles are accepted"] to be published in the online version of the journal, or provide detailed information in their articles on how the data can be obtained. This information should include links to third-party data repositories or detailed contact information for third-party data sources. Data available only on an authormaintained website will need to be loaded onto either the journal's platform or a third-party platform to ensure continuing accessibility. Examples of data types include but are not limited to statistical data files, replication code, text files, audio files, images, videos, appendices, and additional charts and graphs necessary to understand the original research. The editor may consider limited embargoes on proprietary data. The editor can also grant exceptions for data that cannot legally or ethically be released. All data submitted should comply with Institutional or Ethical Review Board requirements and applicable government regulations. For further information, please contact the editorial office at Jovie.McMillan@sagepub.co.uk

\section{Publishing policies}

\subsection{Publication ethics}

SAGE is committed to upholding the integrity of the academic record. We encourage authors to refer to the Committee on Publication Ethics' International Standards for Authors and view the Publication Ethics page on the SAGE Author Gateway

\subsubsection{Plagiarism}

Lupus and SAGE take issues of copyright infringement, plagiarism or other breaches of best practice in publication very seriously. We seek to protect the rights of our authors and we always investigate claims of plagiarism or misuse of published articles. Equally, we seek to protect the reputation of the journal against malpractice. Submitted articles may be checked with duplication-checking software. Where an article is found to have plagiarised other work or included third-party copyright material without permission or with insufficient acknowledgement, or where the authorship of the article is contested, we reserve the right to 
take action including, but not limited to: publishing an erratum or corrigendum (correction); retracting the article; taking up the matter with the head of department or dean of the author's institution and/or relevant academic bodies or societies; or taking appropriate legal action.

\subsection{Contributor's publishing agreement}

Before publication, SAGE requires the author as the rights holder to sign a Journal Contributor's Publishing Agreement. SAGE's Journal Contributor's Publishing Agreement is an exclusive licence agreement which means that the author retains copyright in the work but grants SAGE the sole and exclusive right and licence to publish for the full legal term of copyright. Exceptions may exist where an assignment of copyright is required or preferred by a proprietor other than SAGE. In this case copyright in the work will be assigned from the author to the society. For more information please visit our Frequently Asked Questions on the SAGE Journal Author Gateway.

\subsection{Open Access and author archiving}

Lupus offers optional open access publishing via the SAGE Choice programme. For more information please visit the SAGE Choice website. For information on funding body compliance, and depositing your article in repositories, please visit SAGE Publishing Policies on our Journal Author Gateway.

\subsection{Permissions}

Authors are responsible for obtaining permission from copyright holders for reproducing any illustrations, tables, figures or lengthy quotations previously published elsewhere. For further information including guidance on fair dealing for criticism and review, please visit our Frequently Asked Questions on the SAGE Journal Author Gateway

\section{Preparing your manuscript}

Authors are asked to write their manuscripts in English. Spelling and phraseology should conform either to standard UK English or to standard American English and should be consistent throughout the paper.

The Summary should not exceed 200 words. It should be written in a style that conveys the essential message of the paper in abbreviated form.

The Introduction should assume that the reader is knowledgeable in the field and should therefore be as brief as possible.

In the Materials and methods section, methods that have been published in detail elsewhere should not be described in detail. SI units should be used throughout the text.

Tables and figures should be placed after references and not embedded within the text

\subsection{Word processing formats}

Preferred formats for the text and tables of your manuscript are Word DOC, RTF, XLS. LaTeX files are also accepted. The text should be double-spaced throughout and with a minimum of $3 \mathrm{~cm}$ for left and right hand margins and $5 \mathrm{~cm}$ at head and foot. Text should be standard 10 or 12 point. Word and (La)Tex templates are available on the Manuscript Submission Guidelinespage of our Author Gateway.

\subsection{Artwork, figures and other graphics}

For guidance on the preparation of illustrations, pictures and graphs in electronic format, please visit SAGE's Manuscript Submission Guidelines

Figures supplied in colour will appear in colour online regardless of whether or not these 
illustrations are reproduced in colour in the printed version. For specifically requested colour reproduction in print, you will receive information regarding the costs from SAGE after receipt of your accepted article.

\section{Tables}

Each table should be numbered consecutively with an Arabic numeral. Each should have a separate caption or title. Methods not described in the text and abbreviations should be explained at the foot of the table. Footnotes should be designated by superior lower case letters ( $a, b, c$ etc). Vertical lines should not be inserted in the table. Tables must be referred to specifically in the text of the paper.

\section{Figures}

Lettering should be planned for $50 \%$ reduction; text should be readable after reduction. Figures should be referred to as Figure 1, Figure 2 etc. Figures must be referred to specifically in the text of the paper.

Images should be supplied as bitmap based files (i.e. with .tiff or .jpeg extension) with a resolution of at least $\mathbf{3 0 0} \mathrm{dpi}$ (dots per inch). Line art should be supplied as vector-based, separate .eps files (not as .tiff files, and not only inserted in the Word or pdf file), with a resolution of $\mathbf{6 0 0} \mathrm{dpi}$. Images should be clear, in focus, free of pixilation and not too light or dark.

\section{Colour photographs and Figures - Important information}

Colour photographs and Figures, when accepted, will be published online. In the printed version, they will be in black and white (unless colour prints are paid for). Authors who submit in colour must ensure that their figures are of the highest definition for the black and white version otherwise these may not be accepted. In particular dermatological, immunofluorescent and histological figures must be paid for in colour or omitted from the manuscript and replaced in a descriptive format. If, together with your accepted article, you submit usable colour figures, these figures will appear in colour online regardless of whether or not these illustrations are reproduced in colour in the printed version. For specifically requested colour reproduction in print, you will receive information regarding the possible costs from SAGE after receipt of your accepted article.

\section{The colour printing price is $£ 50$ for the first figure and $£ 25$ for each figure thereafter.}

\subsection{Supplementary material}

This journal is able to host additional materials online (e.g. datasets, podcasts, videos, images etc) alongside the full-text of the article. These will be subjected to peer-review alongside the article. For more information please refer to our guidelines on submitting supplementary files, which can be found within our Manuscript Submission Guidelines page.

\subsection{Journal layout}

Lupus conforms to the SAGE house style. Click here to review guidelines on SAGE UK House Style.

\subsection{Reference style}

Lupus adheres to the SAGE Vancouver reference style. Click here to review the guidelines on SAGE Vancouver to ensure your manuscript conforms to this reference style.

It is important that references comply with the style of the journal. Exhaustive lists should be avoided. References should follow the Vancouver format, listed (double-spaced) in numerical order corresponding to the order of citation in the text.

All authors should be quoted for papers with up to six authors; for papers with more than six authors, the first three only should be quoted followed by et al. 
No issue numbers should be quoted.

Abbreviations for titles of medical periodicals should conform to those used in the latest editions of Index Medicus and Current Contents. The first and last page numbers for each reference should be provided. Abstracts and letters must be identified as such.

Papers in press and papers already submitted for publication may be included in the list of references. No citation is required for work that is not yet submitted for publication.

Personal communications may be allocated a number and included in the list of references in the usual way or simply referred to in the text. Authors must obtain permission from the individual concerned to quote his or her unpublished work.

Examples of References:

Journal article:

1 Derksen RHWM, Bouma BN, Kater L. The association between the lupus anticoagulant and cerebral infarction in systemic lupus erythematosus. Scand J Rheumatol 1986; 15: 179184.

Journal article, in press:

2 Mendonca LLF, Khamashta MA, Nelson-Piercy A, Hunt BJ, Hughes GRV. Nonsteroidal anti-inflammatory drugs as a possible cause for reversible infertility. Rheumatology (in press). Journal article submitted for publication:

3 Khamashta MA, Cervera R, Asherson RA. Association of antibodies against phospholipids with heart valve disease in systemic lupus erythematosus (submitted for publication). Complete book:

4 Wallace DJ, Dubois EL. Dubois' Lupus Erythematosus. Lea \&Febiger, 1987, p 51. Chapter in book:

5 Christian CL. Etiologic hypotheses for systemic lupus erythematosus. In: Lahita RG (ed) Systemic Lupus Erythematosus. Wiley, 1987, 65-79.

Abstract:

6 Valesini G, Luan FL, Falco M. Clonal analysis of affinity purified anticardiolipin antibodies. ClinExpRheumatol 1988; 6: 214 (abstract 102). Letter to the Editor:

7 Sills EM. Systemic lupus erythematosus in a patient diagnosed as having Shulman disease. Arthritis Rheum 1988; 31: 694 (letter).

\subsection{English language editing services}

Authors seeking assistance with English language editing, translation, or figure and manuscript formatting to fit the journal's specifications should consider using SAGE Language Services. Visit SAGE Language Services on our Journal Author Gateway for further information.

\section{Submitting your manuscript}

\subsection{How to submit your manuscript}

Lupusis hosted on SAGE Track, a web based online submission and peer review system powered by ScholarOne ${ }^{\mathrm{TM}}$ Manuscripts. Visit http:/mc.manuscriptcentral.com/lupus to login and submit your article online.

IMPORTANT: Please check whether you already have an account in the system before trying to create a new one. If you have reviewed or authored for the journal in the past year it is likely that you will have had an account created. For further guidance on submitting your manuscript online please visit ScholarOne Online Help.

Note: Online submission and review of manuscripts is now mandatory for all types of papers.

\section{New User Account}

Please log onto the website. If you are a new user, you will first need to create an account. Follow the instructions and please ensure to enter a current and correct email address. 
Creating your account is a three-step process that takes a matter of minutes. When you have finished, your User ID and password is sent immediately via email. Please edit your user ID and password to something more memorable by selecting 'edit account' at the top of the screen. If you have already created an account but have forgotten your details type your email address in the 'Password Help' to receive an emailed reminder. Full instructions for uploading the manuscript are provided on the website.

\section{New Submission}

Submissions should be made by logging in and selecting the Author Centre and the 'Click here to Submit a New Manuscript' option. Follow the instructions on each page, clicking the 'Next' button on each screen to save your work and advance to the next screen. If at any stage you have any questions or require the user guide, please use the 'Get Help Now' button at the top right of every screen. Further help is available through ScholarOne's ${ }^{\circledR}$ Manuscript Central customer support at $+14348172040 \times 167$ or email the editor with your manuscript as an attachment(s) and write a note to explain why you need to submit via this route.

To upload your files, click on the 'Browse' button and locate the file on your computer. Select the designation of each file (i.e. main document, submission form, figure) in the drop down menu next to the browse button. When you have selected all the files you wish to upload, click the 'Upload Files' button.

Review your submission (in both PDF and HTML formats) and then click the Submit button You may suspend a submission at any point before clicking the Submit button and save it to submit later. After submission, you will receive a confirmation e-mail. You can also log back into your author centre at any time to check the status of your manuscript.

Please ensure that you submit editable/source files only (Microsoft Word or RTF) and that your document does not include page numbers; the SAGETRACK system will generate them for you, and then automatically convert your manuscript to PDF for peer review. All correspondence, including notification of the Editor's decision and requests for revisions, will be by email.

If you would like to discuss your paper prior to submission contact the Editor: Prof. GRV Hughes, editorial@lupusjournal.co.uk

\subsection{Title, keywords and abstracts}

Please supply a title, short title, an abstract and keywords to accompany your article. The title, keywords and abstract are key to ensuring readers find your article online through online search engines such as Google. Please refer to the information and guidance on how best to title your article, write your abstract and select your keywords by visiting the SAGE Journal Author Gateway for guidelines on How to Help Readers Find Your Article Online

\subsection{Corresponding author contact details}

Provide full contact details for the corresponding author including email, mailing address and telephone numbers. Academic affiliations are required for all co-authors. These details should be presented separately to the main text of the article to facilitate anonymous peer review.

\section{On acceptance and publication}

\subsection{SAGE Production}

Your SAGE Production Editor will keep you informed as to your article's progress throughout the production process. Proofs will be sent by PDF to the corresponding author and should be returned promptly. 


\subsection{Access to your published article}

SAGE provides authors with online access to their final article.

\subsection{Online First publication}

Online First allows final revision articles (completed articles in queue for assignment to an upcoming issue) to be published online prior to their inclusion in a final journal issue which significantly reduces the lead time between submission and publication. For more information please visit our Online First Fact Sheet

\section{Further Information}

If you would like to discuss your paper prior to submission, please contact the Editor:

Prof. GRV Hughes

Lupus Research Unit

The Rayne Institute

St Thomas' Hospital

London SE1 7EH, UK

Tel: 442076202567

Fax: 442076202658

editorial@lupusjournal.co.uk

Managing Editor: Dr Maria Laura Bertolaccini

Editorial Assistant: MrsDenzil Fletcher

Contact information for the Publisher:

Jovie McMillan

jovie.mcmillan@sagepub.co.uk 


\section{Appendix 3: Ethical approvals}

Includes approval from the Postgraduate committee, BREC (original approval, recertification and amendments), Inkosi Albert Luthuli Central Hospital and KwaZulu-Natal Department of Health.

6 July 2010

Professor A Assounga

Department of Medicine

Nelson R Mandela School of Medicine

Dear Professor Assounga

PROTOCOL: "The Severity and Outcome of Lupus Nephritis in Clinical Practice."

Student: PG Mody, student number: 973122501 . (Medicine).

The Postgraduate Education Committee ratified the approval of the abovementioned study on 06 July 2010

Please note:

- The Postgraduate Education Committee must review any changes made to this study.

- The study may not begin without the approval of the Biomedical Research Ethics Committee.

May I take this opportunity to wish the student every success with the study.

Yours sincerely

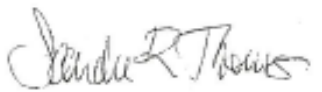

Professor SR Thomson

Dean's Assistant: MMed Programmes

Postgraduate Education Committee

CC. Dr PG Mody
UNIVERSITY OF KWAZULU-NATAL

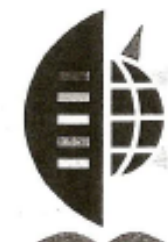

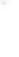


27 August 2010

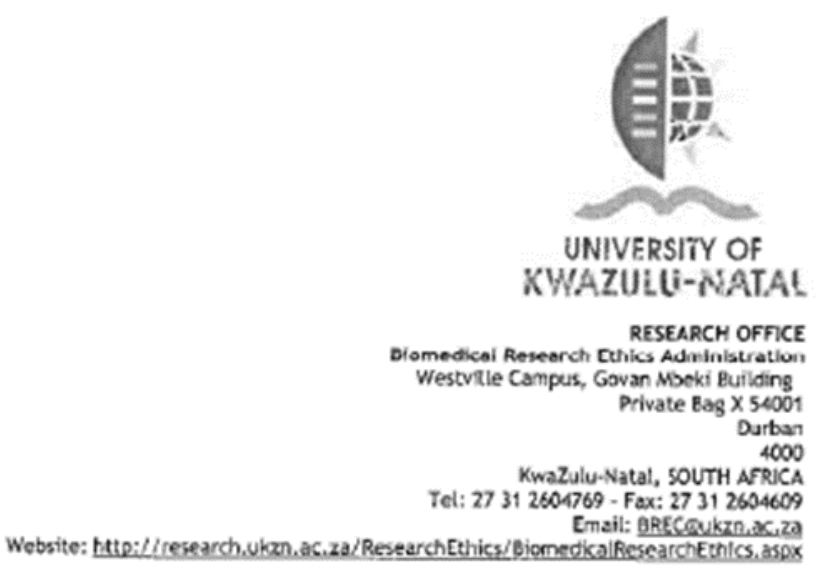

\author{
Dr. PG Mody \\ Nephrology \\ Dept of Internal Medicine \\ Nelson R. Mandela School of Medicine \\ University of KwaZulu-Natal \\ Dear Dr Mody
}

PROTOCOL: The severity and Outcome of Lupus Nephritis in Clinical Practice. REF: BE088/010

\title{
EXPEDITED APPLICATION
}

A sub-committee of the Biomedical Research Ethics Committee has considered and noted your application dated 13 April 2010.

The study was provisionally approved pending appropriate responses to queries raised. Your responses dated 21 July 2010 to queries raised on 21 June 2010 have been noted by a sub-committee of the Biomedical Research Ethics Committee. The conditions have now been met and the study is given full ethics approval and may begin as from 27 August 2010.

This approval is valid for one year from 27 August 2010. To ensure uninterrupted approval of this study beyond the approval expiry date, an application for recertification must be submitted to BREC on the appropriate BREC form 2-3 months before the expiry date.

Any amendments to this study, unless urgently required to ensure safety of participants, must be approved by BREC prior to implementation.

Your acceptance of this approval denotes your compliance with South African National Research Ethics Guidelines (2004), South African National Good Clinical Practice Guidelines (2006) (if applicable) and with UKZN BREC ethics requirements as contained in the UKZN BREC Terms of Reference and Standard Operating Procedures, all available at http://research,ukzn.ac.za/ResearchEthics11415. aspx. 
BREC is registered with the South African National Health Research Ethics Council (REC-290408-009). BREC has US Office for Human Research Protections (OHRP) Federal-wide Assurance (FWA 678).

The sub-committee's decision will be RATIFIED at a full sitting of the Biomedical Research Ethics Committee meeting to be held on 12 October 2010.

We wish you well with this study. We would appreciate receiving copies of all publications arising out of this study.

Yours sincerely

Protessor D.R Wassenaar

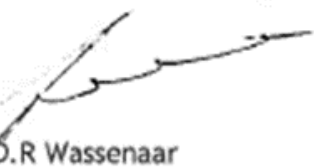

Chair: Biomedical Research Ethics Committee 


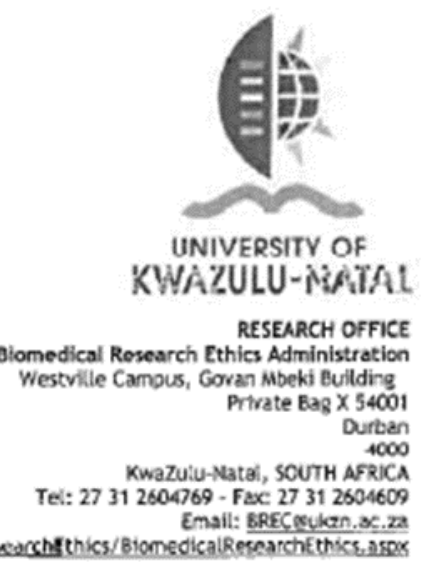

01 November 2010

Dr. PG Mody

Nephrology

Dept of Internal Medicine

Nelson R. Mandela School of Medicine

University of KwaZulu-Natal

Dear Dr Mody

PROTOCOL: The severity and Outcome of Lupus Nephritis in Clinical Practice.

REF: BE088/010

\section{EXPEDITED APPLICATION - RATIFICATION}

This letter serves to notify you that at a full sitting of the Biomedical Research Ethics Committee meeting held on 19 October 2010, the Committee RATIFIED the sub-committee's decision to approve the above study.

NB: The BREC meeting did not take place on 12 October 2010 as noted previously due to unforeseen circumstances.

Yours sincerely

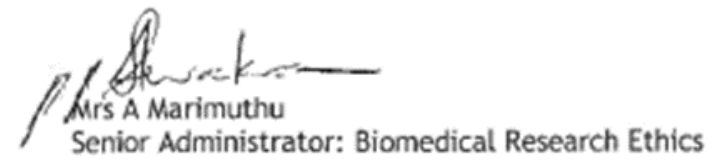




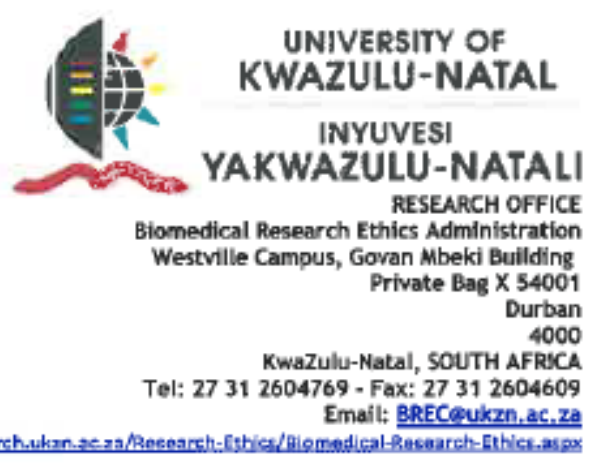

\section{September 2016}

Dr. PG Mody

Nephrology

Dept of Internal Medicine

Nelson R. Mandela School of Medicine

University of KwaZulu-Natal

Dear Dr Mody

PROTOCOL: The severity and Outcome of Lupus Nephritis in Clinical Practice. REF: BE088/010

\section{RECERTIFICATION APPLICATION APPROVAL NOTICE}

Approved:

27 August 2016

Expiration of Ethical Approval: 26 August 2017

I wish to advise you that your application for Recertification received on 08 September 2016 for the above protocol has been noted and approved by a sub-committee of the Biomedical Research Ethics Committee (BREC) for another approval period. The start and end dates of this period are indicated above.

BREC condones the lapse period of certification.

If any modifications or adverse events occur in the project before your next scheduled review, you must submit them to BREC for review. Except in emergency situations, no change to the protocol may be implemented until you have received written BREC approval for the change.

This approval will be ratified by a full Committee at its next meeting taking place on 11 October 2016.

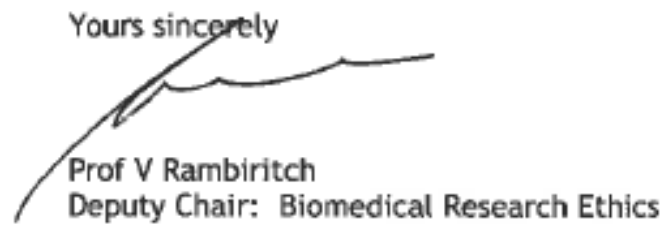




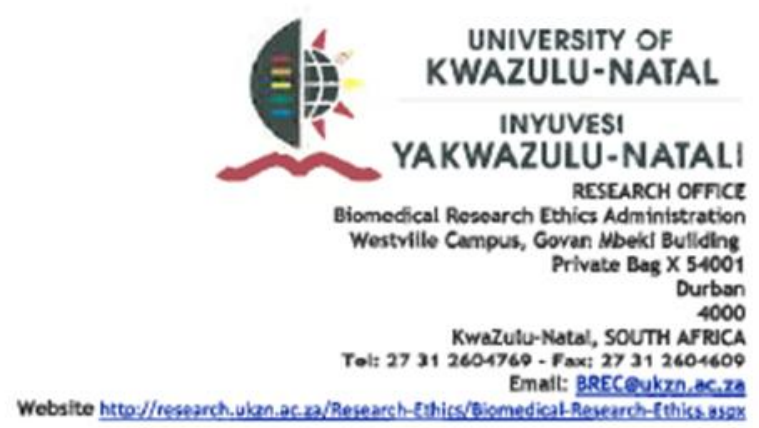

23 November 2016

Dr. PG Mody

Nephrology

Dept of Internal Medicine

Nelson R. Mandela School of Medicine

University of KwaZulu-Natal

Dear Dr Mody

PROTOCOL: The severity and Outcome of Lupus Nephritis in Clinical Practice. REF: BE088/010

Your correspondence received on 07 November 2016 submitting an application for Amendments for the above study has been noted and approved by a sub-committce of the Biomedical Research Ethics Committee.

This approval will be ratified at the next BREC meeting to be held on 13 December 2016.

Yours sincerely

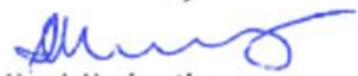

Mrs A Marimuthu

Senior Administrator: Biomedical Research Ethics 


\section{DEPARTMENT OF HEALTH}

PROVINGE OF KWAZULU-NATAL

INKOSI ALBERT LUTHULI CENTRAL HOSPITAL OFFICE OF THE MEDICAL MANAGER

800 Bellair Road, Mayvile, 4058

Private lag $\times 03$, Mayville, 4058

Tel: 0312401059

Email. Ursulanungualchico.za

Fax. 0312401050

\section{July 2010 \\ Dr P G Mody \\ Renal Unit \\ IALCH}

Dear Dr Mody

\section{Re: Ref No: BFossio10: The severity and Ontcome of I upus Nephritis in Clinical Practice}

As per the policy of the Provincial Health Research Committee (PHRC), you are hereby granted permission to conduct the above mentioned research once all relevant documentation has been submitted to PHRC inclusive of Full Ethical Approval.

Kindly note the following.

1. The research should adhere to all policies, procedures, protocols and guidelines of the KwaZulu-Natal Department of Health.

2. Research will only commence once the PHRC has granted approval to the researcher

3. The researcher must ensure that the Medical Manager is informed before the commencement of the research by means of the approval letter by the chairperson of the PHRC.

4. The Medical Manager expects to be provided feedback on the findings of the research.

5. Kindly submit your research to:

The Secretariat

Health Research \& Knowledge Management

330 Langaliballe Strect, Pietermaritzburg, 3200

Private Bag X9501, Pietermaritzburg , 3201

Tel: 033395-3123, Fax 033394-3782

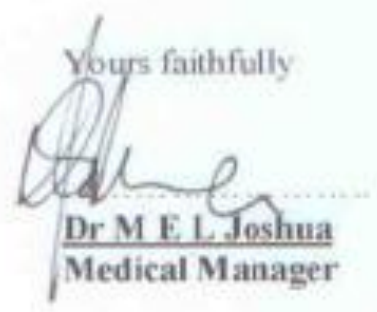




\section{DEPARTMENT OF HEALTH}

PROVINCE OF KWAZULU-NATAL

INKOSI ALBERT LUTHULI CENTRAL HOSPITAL

OFFICE OF THE MEDICAL MANAGER

800 Bellair Road, Mayville, 4058

Private Baq X03, Mayville 4058

Tel: 0312401059 Fax. 0312401050

Email. ursulanun (8)ialch. 00 za

\section{Reference: BEO8s 010}

Enquiriex Dr ME L. Jowlea

7 July 2010

Dr P G Mody

Renal Unit

IALCH

Dear Dr Mody

\section{RE: PERMISSION TO CONDUCT RESEARCH AT IALCH REF-BE0s8/010}

I have pleasure in informing you that permission has been granted to you by the Medical Manager to conduct research on

Kindly take note of the following information before you continue:

1. Please ensure that you adhere to all the policies, procedures, protocols and guidelines of the Department of Health with regards to this research.

2. This research will only commence once this office has feceived confirmation from the Provincial Health Research Committee in the KZN Department of Health.

3. Kindly ensure that this office is informed before you commence your research

4. The hospital will not provide any resources for this research.

5. You will be expected to provide feedback once your research is complete to the Medical Manager

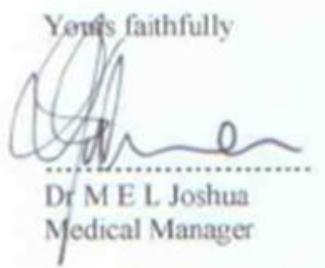


Appendix 4: Data collection tools

\section{DATA COLLECTION FORM}

\section{(A) DEMOGRAPHIC INFORMATION}

KZ NO

STUDY NO

RACE: 1 = AFRICAN ; 2 = COLOURED ; 3 = INDIAN ; 4 = WHITE ; 5 = OTHER

ADDRESS

AGE (YEARS)

SEX : MALE = 1 ; FEMALE = 2

(B) CORMORBITIES

HYPERTENSION

DIABETES MELLITUS

DYSLIPIDAEMIA

ANALGESIC NEPHROPATHY

URATE NEPHROPATHY

CHRONIC GLOMERULONEPHRITIS

HIV

HEPATITIS

OBESITY

PREGNANCY

OTHER

\section{(C) DIAGNOSIS OF LUPUS NEPHRITIS}

DATE OF DIAGNOSIS (DDMMYEAR)

BASELINE FINDING AT DIAGNOSIS

Proteinuria Yes $=1 ; \mathrm{No}=2$

Quantity of protein/24 hours

Urine dipstix protein $1=$ nil ; $2=$ trace ; $3=+; 4=++; 5=+++; 6=++++$

Blood $1=\mathrm{Nil} ; 2=$ trace $; 3=+; 4=++; 5=+++; 6=++++$

Casts 1 = Nil ; 2 = RBC ; $3=$ Granular ; 4 = Hyaline ; 5 = Combination

RAISED UREA YES = 1 ; NO = 2

BLOOD PRESSURE AT DIAGNOSIS

UREA IN MMOL/L

RAISED CREATININE YES $=1 ;$ NO $=2$

CREATININE IN $\mu \mathrm{MOL} / \mathrm{L}$

REDUCED EGFR YES $=1 ; \mathrm{NO}=2$

eGFR in $\mathrm{ml} / \mathrm{min}$

REDUCED CREATININE CLEARANCE YES $=1 ;$ NO $=2$

CREATININE CLEARENCE IN ML/MIN

REDUCED ISOTOPE GFR YES $=1$; NO $=2$

GFR IN ML/MIN

ULTRASOUND KIDNEYS DONE YES $=1 ; \mathrm{NO}=2$

RIGHT KIDNEY SIZE (CM)

LEFT KIDNEY SIZE (CM)

\begin{tabular}{|l|l|l}
\hline & YES=1 NO=2 & DURATION AND TREATMENT \\
\hline & & \\
\hline & & \\
\hline & & \\
\hline & & \\
\hline & & \\
\hline & & \\
\hline
\end{tabular}


RENAL BIOPSY YES $=1 ;$ NO $=2$

IF YES, THEN RENAL BIOPSY RESULT

LM

EF

IF

IF NO BIOPSY DONE, EVIDENCE FOR DIAGNOSIS OF LUPUS NEPHRITIS

PATIENT CLASSIFICATION OF LUPUS NEPHRITIS BASED ON RENAL BIOPSY AT DIAGNOSIS YES = 1 ; NO = 2

CLASS I

CLASS II

CLASS III

CLASS IV

CLASS V

CLASS VI (ERD)

CLASS III + V

CLASS IV + V

OTHER:

\section{(D) LABORATORY RESULTS}

\begin{tabular}{|l|l|l|l|l|l|}
\hline & AT DIAGNOSIS & 6 MONTHS & 12 MONTHS & AT RX CHANGE & AFTER 6 MONTHS \\
\hline SCREATININE (UmOI/L) & & & & & \\
\hline sUREA (mmol/L) & & & & & \\
\hline eGFR (MDRD) & & & & & \\
\hline ISOTOPE GFR & & & & & \\
\hline URINE DIPSTIX & PROT & PROT & PROT & PROT & PROT \\
\hline & BLD & BLD & BLD & BLD & BLD \\
\hline URINE MICRO. & & & & & \\
\hline 24HR UTP & & & & & \\
\hline 24hr CrCI & & & & & \\
\hline KIDNEY SIZES & (R) & (R) & (R) & (R) & (R) \\
\hline (L) & (L) & (L) & (L) & (L) \\
\hline ANF +VE Y=1 N=2 & & & & & \\
\hline ANF TITRE STAINING PATTERN & & & & & \\
\hline DS DNA & & & & & \\
\hline ENA & & & & & \\
\hline COMPLEMENT & C3 & C3 & C3 & C3 & C3 \\
\hline & C4 & C4 & C4 & C4 & C4 \\
\hline ESR & & & & & \\
\hline CRP & & & & & \\
\hline RENAL BIOPSY & & & & & \\
\hline HAEMOGLOBIN & & & & & \\
\hline WHITE BLOOD CELLS & & & & & \\
\hline PLATELETS & & & & & \\
\hline
\end{tabular}




\begin{tabular}{|l|}
\hline TOTAL CHOLESTEROL \\
\hline TRIGLYCERIDES \\
\hline HDL \\
\hline LDL
\end{tabular}

OTHER

\section{(E) FEATURES OF SYSTEMIC LUPUS ERYTHEMATOSUS}

(please indicate YES $=1$ and NO =2)

\begin{tabular}{|c|c|c|}
\hline \multirow{2}{*}{$\begin{array}{l}\text { Clinical Features } \\
\text { 1. Malar rash }\end{array}$} & Present at time of diagnosis & Present at time of referral/ biopsy \\
\hline & & \\
\hline 2. Discoid rash & & \\
\hline 3. Photosensitivity & & \\
\hline 4. Oral ulcers & & \\
\hline 5. Serositis & & \\
\hline 6. Arthritis/ arthralgia & & \\
\hline 7. Renal : & & \\
\hline 8. CNS : & & \\
\hline 9. Haematology & & \\
\hline (i) Haemolytic anemia & & \\
\hline (ii) Thrombocytopenia & & \\
\hline (iii) Leucopenia & & \\
\hline (iv )Lymphopenia & & \\
\hline 10. Immunology & & \\
\hline (i)ds DNA & & \\
\hline (ii)Sm antibody & & \\
\hline (iii) LA & & \\
\hline (iv) ACA & & \\
\hline (v) RPR & & \\
\hline 11. ANF & & \\
\hline a) Titre & & \\
\hline Number of criteria & & \\
\hline Other manifestations & & \\
\hline Alopecia & & \\
\hline Cutaneous vasculitis & & \\
\hline Raynauds & & \\
\hline OTHERS (SPECIFY) & & \\
\hline & & \\
\hline & & \\
\hline & & \\
\hline & & \\
\hline
\end{tabular}




\begin{tabular}{|c|c|c|c|c|c|c|}
\hline \multicolumn{7}{|c|}{ (F) TREATMENT } \\
\hline DRUG & $\begin{array}{l}\text { Yes1/ } \\
\text { No } 2\end{array}$ & Dose & Start & Stop & $\begin{array}{c}\text { REASON FOR } \\
\text { TREATMENT CHOICE }\end{array}$ & $\begin{array}{c}\text { REASON FOR } \\
\text { DISCONTINUATION }\end{array}$ \\
\hline \multicolumn{7}{|l|}{ Prednisone } \\
\hline \multicolumn{7}{|c|}{ Methyl prednisone } \\
\hline \multicolumn{7}{|l|}{ IV CYC } \\
\hline \multicolumn{7}{|l|}{ Azathioprine } \\
\hline \multicolumn{7}{|l|}{ MMF } \\
\hline OTHER & & & & & & \\
\hline
\end{tabular}

\section{(G) DRUG COMPLICATIONS: YES = 1 ; NO = 2}

Prednisone

Methyl prednisone

IV CYC

Azathioprine

MMF

OTHER

(H) OUTCOMES: YES = 1 ; NO = 2

COMPLETE

INCOMPLETE

NON RESPONDER

\section{(I) IF NON RESPONDER, RENAL REPLACEMENT THERAPY. YES =1;NO =2}

\section{HAEMODIALYSIS}

PERITONEAL DALYSIS

RENAL TRANSPLANTATION

\section{(J) OTHER}




\section{Abbreviations}

$\begin{array}{ll}\text { ACR } & \text { American College of Rheumatology } \\ \text { ACA } & \text { Anti-cardiolipin antibody } \\ \text { ALMS } & \text { Aspreva Lupus Management Study } \\ \text { ANF } & \text { Antinuclear factor antibodies } \\ \text { anti-dsDNA } & \text { Anti-double stranded DNA antibodies } \\ \text { anti-Sm } & \text { Anti-Smith antigen antibodies } \\ \text { C3 } & \text { Complement factor } 3 \\ \text { C4 } & \text { Complement factor 4 } \\ \text { CKD } & \text { Chronic kidney disease } \\ \text { CNI } & \text { Calcineurin inhibitor } \\ \text { CR } & \text { Complete responder } \\ \text { CYC } & \text { Cyclophosphamide } \\ \text { eGFR } & \text { Estimated glomerular filtration rate } \\ \text { ENA } & \text { Extractable nuclear antigen } \\ \text { ERA-EDTA } & \text { European Renal Association - European Dialysis and Transplant } \\ & \text { Association } \\ \text { EULAR } & \text { European League Against Rheumatism } \\ \text { HIV } & \text { Human Immunodeficiency Virus } \\ \text { HBV } & \text { Hepatitis B Virus } \\ \text { HCV } & \text { Hepatitis C Virus } \\ \text { IALCH } & \text { Inkosi Albert Luthuli Central Hospital } \\ \text { ISN/RPS } & \text { International Society of Nephrology/Renal Pathology Society } \\ \text { KDIGO } & \text { Kidney Disease, Improving Global Outcomes } \\ \text { KDOQI } & \text { Kidney Disease Outcomes Quality Initiative } \\ \text { LUMINA } & \text { Lupus in Minorities: Nature versus Nuture } \\ \text { LUNAR } & \text { Lupus Nephritis Assessment with Rituximab } \\ \text { LN } & \text { Lupus nephritis } \\ \text { MDRD } & \text { Modified Diet in Renal Disease } \\ \text { MMF } & \text { Mycophenolate mofetil } \\ \text { NIH } & \text { National Institute of Health } \\ \text { NKF } & \text { National Kidney Foundation } \\ \text { NR } & \text { Non responder } \\ \text { PR } & \text { Partial responder } \\ \text { RPR } & \text { Rapid plasma regain } \\ \text { RF } & \text { Rheumatoid factor } \\ \text { SD } & \text { Standard Deviation } \\ \text { SLE } & \text { Systemic lupus erythematosus } \\ \text { UK } & \text { United Kingdom } \\ \text { USA } & \text { United States of America } \\ \text { UPCR } & \text { Urine protein creatinine ratio } \\ \text { WHO } & \text { World Health Organisation } \\ & \end{array}$

